\title{
Enhanced water uptake in the longitudinal direction by shiitake mycelium in shiitake cultivation logs: increase in effective diffusion coefficient based on mass of liquid water uptake
}

\author{
Kuniyasu Ogawa ${ }^{1}$ D $\cdot$ Takeshi Yashima $^{2}$
}

Received: 26 January 2021 / Accepted: 14 June 2021 / Published online: 9 July 2021

(C) The Author(s), under exclusive licence to Springer-Verlag GmbH Germany, part of Springer Nature 2021

\begin{abstract}
In the cultivation of shiitake mushrooms (Lentinula edodes), the farmer needs to know the time needed to water in order to adjust the water content of the logs. In this study, six test logs (Quercus serrata, diameter of 38-48 mm, length of 110$118 \mathrm{~mm}$ ) were used, of which some were dried, some had shiitake mycelia grown on them, and some had mold generated on them. Liquid water was supplied to the test logs by placing the longitudinal direction of the test logs along the line of gravity and immersing the bottom of the test logs in water. Water uptake mass of the test logs was measured for $20 \mathrm{~h}$. The effective diffusion coefficient, $D_{\text {eff }}$, was calculated from the change in time of the water uptake mass using Fick's diffusion law. The $D_{\text {eff }}$ of test logs in which shiitake mycelium grew were $1.5-3.4 \times 10^{-8} \mathrm{~m}^{2} / \mathrm{s}$, and the values were 2.4-4.7 times higher than that for the dried log. On the other hand, the $D_{\text {eff }}$ of the moldy logs were $6.7-9.7 \times 10^{-10} \mathrm{~m}^{2} / \mathrm{s}$, which was $0.058-0.081$ times that of dry test logs. Based on observation of water penetration into logs by magnetic resonance imaging (MRI) and an optical microscope, it is believed that the driving force behind liquid water rising in the longitudinal direction in the test log is the capillary force acting on a three-phase interface consisting of the inner wall surface of the vessel, liquid water and air.
\end{abstract}

Kuniyasu Ogawa

ogawa@mech.keio.ac.jp

Takeshi Yashima

yashima2@pref.ishikawa.lg.jp

1 Department of Mechanical Engineering, Keio University, 3-14-1 Hiyoshi, Kouhoku-ku, Yokohama, Kanagawa 223-8522, Japan

2 Ishikawa Agriculture and Forestry Research Center, 1-1 Mizuho, Noto-chou, Housu-gun, Ishikawa 927-0311, Japan 


\section{Introduction}

The total amount of fresh shiitake mushrooms produced in Japan in 2019 was 71,000 tons (MAFF 2019). About $8 \%$ was cultivated using hardwood logs. In Ishikawa Prefecture, shiitake mushrooms are cultivated on native Quercus serrata logs. In log cultivation, Quercus serrata is cut down in autumn, the logs are dried outdoors in winter, and they are inoculated with a strain of shiitake mushrooms in the spring (Przbylowicz and Donoghue 1988; Wasser 2005; Tokimoto 2010). Logs are placed outdoors (typically in the open forest) and through sunlight, rainfall and watering are repeatedly dried and absorb liquid water. Shiitake mycelium grows and expands in the log in an environment where the water content and temperature of the $\log$ is changing. During growth, the shiitake mycelium absorbs nutrients by decomposing polysaccharides such as cellulose, hemicellulose and lignin. In winter, the shiitake mycelium produces about 100 to 150 fruiting bodies per log. Shiitake mushrooms can be harvested every winter for five years.

On the other hand, about $92 \%$ of shiitake mushrooms is cultivated using a woodchip block in which wood chips having a size of about $5 \mathrm{~mm}$ are packed in a plastic bag (Przbylowicz and Donoghue 1988; Wasser 2005). In woodchip block cultivation, shiitake mycelia are grown in a humid room at about $20{ }^{\circ} \mathrm{C}$, and the mushrooms are harvested in 3 months. Compared to log cultivation, woodchip block cultivation has the advantage of being able to provide a stable harvest of a large amount of shiitake mushrooms in a short period of time, but the profits of farmers are not high because of the low price of shiitake mushrooms produced by woodchip block cultivation. On the other hand, log cultivation shiitake mushrooms are popular because of their good flavor and texture (MEXT 2016), and they are sold at a price several times higher than that of shiitake mushrooms grown in woodchip blocks. In particular, dried log cultivation shiitake mushrooms are sold as gifts at prices 10 times higher.

Although log cultivation is laborious and time-consuming, shiitake mushrooms grown via log cultivation are an important income source for farmers as a highvalue-added crop. However, farmers need to possess advanced skills to harvest large and well-shaped shiitake mushrooms through the log cultivation method. The reason is that it is difficult to control the water content of logs placed outdoors, and the growth of shiitake mycelium in a log is suppressed by the propagation of other wood-rotting fungi. To adjust the water content of logs placed in the open forest, the farmer regulates shade and ventilation when drying the logs, and sometimes sprinkles liquid water on the logs.

Watering time is very important for adjusting the water content of the logs in shiitake cultivation. Since the permeation rate of liquid water into the log differs depending on the shiitake mycelium growing in the log, the watering time differs depending on the growth area of the shiitake mycelium. Farmers know this empirically; however, there have been no reports of quantitative measurements on the penetration rate of liquid water into logs. It has been found that the presence of brown rot fungi changes the penetration of liquid water into a piece of wood (Frankl 2013). However, shiitake mycelium was not used in the report 
and the effective diffusion coefficient of liquid water was not calculated from the measured water uptake. In addition, although many studies have quantitatively evaluated the liquid water penetrating into wood pieces by the effective diffusion coefficient (Burr and Stamm 1956; Krus and Kunzel 1993; Kumaran 1999; Candanedo and Derome 2005; Khazaei 2008; Gezici-Koç et al. 2017; Hunter 1993; Noorolahi et al. 2008; Okoh 2014; Zhou et al. 2018), there has been no report evaluating how much the effective diffusion coefficient of liquid water is increased by the presence of shiitake mycelium growing in logs.

In this study, when the bottom surface of a test log (Quercus serrata) placed along the direction of gravity was immersed in liquid water, the effective diffusion coefficient of the liquid water penetrating into the logs was calculated using an uptake mass method (called mass method). Then, the shiitake mycelium was inoculated on the same test log and grown, and the effective diffusion coefficient of the liquid water penetrating into the test log was determined. The effective diffusion coefficient of liquid calculates water using a one-dimensional unsteady-state diffusion equation called Fick's laws of diffusion (Burr and Stamm 1956; Hunter 1993; Krus and Kunzel 1993; Kumaran 1999). On the other hand, the water penetration mechanism into a log in the longitudinal direction due to capillary force has been demonstrated in several papers (Zhou et al. 2018, 2019). Zhou et al. (2019) used $\mathrm{X}$-ray microcomputed tomography imaging to visualize water rising in vessels of a hornbeam sample. On the other hand, in the present study, optical microscope was used to observe the water rising to the top surface of the log disk from the bottom. Based on observations with the optical microscope and decrease in the NMR signal from the free water observed by MRI, a water penetration model was proposed, where the liquid water rises in vessels in the test log as a result of capillary force and diffuses to the fibers in the latewood region.

\section{Materials and methods}

\section{Test log dried indoors}

Six test logs (Quercus serrata) with bark were used as shown in Table 1. In log cultivation, it is common to use logs with a diameter of 100-200 mm and a length of $900 \mathrm{~mm}$, but in this study, small logs were used that can be measured by MRI. Table 1 shows the size of the six test logs (samples A-F), the presence or absence of inoculation of shiitake mycelium, and the number of growth days.

The test logs were dried indoors $\left(23.5^{\circ} \mathrm{C}\right.$ about $\left.35 \% \mathrm{RH}\right)$ for $12-15$ months without a dryer. By measuring the mass of the completely dried test log after all the experiments were completed, the water content, $\beta_{\text {Mass }}[-]$, of the test log was calculated using the equation below:

$$
\beta_{\text {Mass }}=\frac{M_{\mathrm{Wet}}-M_{\text {Dry }}}{M_{\text {Dry }}}
$$


Table 1 Size of six test logs, experimental number, inoculation, and growth days of shiitake mycelium in three test logs

\begin{tabular}{|c|c|c|c|c|c|c|}
\hline Sample \# & $\begin{array}{l}\text { Outer } \\
\text { diameter } \\
{[\mathrm{mm}]}\end{array}$ & $\begin{array}{l}\text { Length } \\
{[\mathrm{mm}]}\end{array}$ & $\begin{array}{l}\text { cross-sectional } \\
\text { area of the } \\
\text { bottom surface } \\
{\left[\mathrm{cm}^{2}\right]}\end{array}$ & $\begin{array}{l}\text { Experiment \# } \\
\# 2 \text { : (drying days) }\end{array}$ & Inoculation & $\begin{array}{l}\text { Growth } \\
\text { days }\end{array}$ \\
\hline A & $43-46$ & 118 & 15.64 & $\begin{array}{l}\text { Dry \#1, \#2 (21), } \\
\text { Mycelium }\end{array}$ & $\begin{array}{l}\text { Shiitake } \\
\text { mycelium }\end{array}$ & 68 days \\
\hline $\mathrm{B}$ & $45-46$ & 112 & 18.78 & Dry \#1, Mycelium & $\begin{array}{l}\text { Shiitake } \\
\text { mycelium }\end{array}$ & 34 days \\
\hline $\mathrm{C}$ & $44-47$ & 121 & 15.63 & $\begin{array}{l}\text { Dry \#1, \#2 (101), } \\
\text { Mycelium }\end{array}$ & $\begin{array}{l}\text { Shiitake } \\
\text { mycelium }\end{array}$ & 87 days* \\
\hline $\mathrm{D}$ & $46-48$ & 110 & 18.22 & Dry \#1, Mold & Non (Mold) & 75 days \\
\hline $\mathrm{E}$ & $38-42$ & 112 & 13.04 & Dry \#1, Mold & Non (Mold) & 24 days \\
\hline $\mathrm{F}$ & $46-48$ & 114 & 18.11 & Dry \#1, Mold & Non (Mold) & 22 days \\
\hline
\end{tabular}

*Test log was kept in a $5{ }^{\circ} \mathrm{C}$ constant temperature incubator for 54 days because of the closure of the university for COVID-19

where $M_{\text {Wet }}[\mathrm{kg}]$ is the mass of the piece of test log containing water, and $M_{\text {Dry }}$ $[\mathrm{kg}]$ is the mass of the piece of test log dried completely in a dryer $\left(102^{\circ} \mathrm{C}, 24 \mathrm{~h}\right)$. $\left(M_{\mathrm{Wet}}-M_{\mathrm{Dry}}\right)$ is equal to the mass $M_{\mathrm{H} 2 \mathrm{O}}[\mathrm{kg}]$ of water contained in the test log piece.

\section{Cross-sectional surface of test log}

A typical micrograph of the cross-sectional surface of a test log is shown in Fig. 1a. An optical microscope (SANWA SUPPLY INC. 400-CAM058) was used for observing the cutting surface of the test logs. In the cross section of a test log (Quercus serrata), a large number of earlywood vessels with diameter of 100-200 $\mu \mathrm{m}$ are lined up in a ring shape. On the other hand, in the latewood region, there are wood fibers and a large number of agglomerated latewood vessels (white strip-shaped area in the micrograph) with diameter of $10-50 \mu \mathrm{m}$.

\section{Setup for the water uptake experiment}

The arrangement in a water uptake experiment with the bottom of the test log immersed in liquid water is shown in Fig. 1b. The longitudinal $(y)$ direction of the test $\log$ was adjusted to the direction of gravity. The bottom surface $(y=0)$ of the test $\log$ was immersed by about $1 \mathrm{~mm}$ in a liquid water reservoir. Liquid water was constantly supplied to the water reservoir so that the inundation depth of $1 \mathrm{~mm}$ was kept constant.

Water uptake experiments were performed as shown in Table 1. To begin with, the first water uptake experiment (Dry \#1) was carried out using dried test logs without shiitake mycelium. Then, prior to the second water uptake experiment (Dry \#2), the test logs were dried in a room at a temperature of $23.5^{\circ} \mathrm{C}$ and humidity of about $35 \%$ RH for 21 or 101 days as shown as drying days in Table 1 . When the test 
$\log$ had been dried for 20 days, its water content reached almost a constant value. In the "Experiment \#" column of Table 1, the number of water uptake experiments conducted is listed. "Dry \# 1" is listed in the table when the water uptake experiment was conducted only once using a dried test log. "Dry \# 1, \# 2" is listed in the table when two experiments were performed. After drying the test logs, the water content, $\beta_{\text {Mass }}$, of the test logs was about 13 to $14 \%$, and then the second water uptake experiment (Dry \#2) was carried out following the same procedure as the first experiment (Dry \#1).

\section{Test log in which shiitake mycelium or mold grew}

After conducting a water uptake experiment (Dry \#1 and \#2) on three test logs (samples A, B, C) without shiitake mycelium, the test logs were inoculated. After the water uptake experiment (Dry \#2), the bottom surface $(y=0)$ of the test log was inoculated with shiitake mycelium (XR1, Mori \& Company, Limited.). The inoculated test log was placed in an acrylic folder to prevent drying and used for MRI measurement. The test log in the acrylic folder was placed in a constant temperature incubator (temperature $21{ }^{\circ} \mathrm{C}$, humidity $75 \%$ ), and the shiitake mycelium was grown for 68 days. The test $\log$ placed in the incubator dried at a rate of 0.2 to $0.3 \mathrm{~g}$ / day. The test log was watered once every five days to maintain the water content of the test log so that the shiitake mycelium could grow. After water supply, the mass of the test log was measured with an electric balance (Shimadzu CORPORATION TX2202N). The mass of the test log was kept almost constant by water supply. After mass measurement, the test log was returned to the incubator.

\section{MRI measurement for the identification of the area in which mycelium grows in the test log}

In our previous study, we developed a method for visualizing the growth areas of shiitake mycelium and mold in a log by using MRI (Ogawa and Yashima 2020, 2019). In this study, the MRI visualization method was applied to the six test logs (Samples A to F) to identify the growth areas of the shiitake mycelium and mold.

(a)

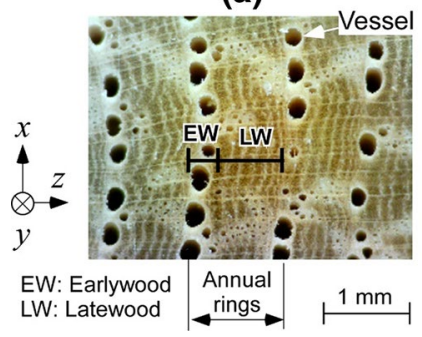

(b)

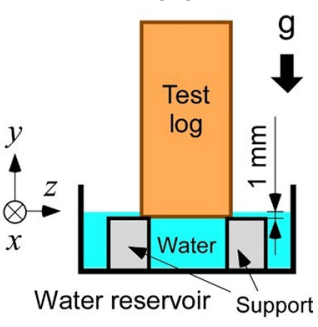

Fig. 1 a Typical optical micrograph of a cross section of the test log (Quercus serrata), b arrangement when immersing the bottom of the test log in liquid water in a water uptake experiment 


\section{MRI measurement system}

The MRI measurement system consisted of a permanent magnet with magnetic field strength of 1 Tesla and $110 \mathrm{~mm}$ air-gap (NEOMAX Engineering) and an MRI console (built in the laboratory). Detailed descriptions of the MRI measurement system and the pulse sequence for the MRI measurement are described in a previous study (Ogawa and Yashima 2020).

\section{Measurement parameters for MRI}

MR images were acquired using five sequences (Sequences (a-e)) shown in Table 2 for identification of the fungi growth areas in the six test logs. Sequences (a), (b), (d), and (e) are multi-slice sequences based on simple spin echo (Ogawa and Yashima 2020).

The sequences (a) and (e) are high spatial resolution sequences. In these sequences, the echo time, $T E$, was set to a long $18 \mathrm{~ms}$ in order to secure a long readout time. The sequences $(b-d)$ are high sensitivity sequences characterized by the shorter echo time in order to acquire stronger echo signal.

The sequence (c) is based on the saturation method. The sequence (c) is devised by applying the saturation method by adding a pre- $90^{\circ}$ excitation pulse to sequence (b), and changing the waiting time, $\tau_{\text {pre }}$, which is the time between the pre- $90^{\circ}$ excitation pulse and the $90^{\circ}$ excitation pulse. By measuring with MRI sequence (c) and changing the waiting time, $\tau_{\text {pre }}$, in ten steps from 20 to $250 \mathrm{~ms}$, ten $T_{1}$-weighted images of water in test log can be obtained (Kleinberg 1995; Callaghan 2006). The $T_{1}$ relaxation time constant of each pixel can be obtained from the signal intensities of the pixel at the same position for all eleven MR images. Based on the $T_{1}$ relaxation time constant and signal intensity of the MR image, the amount of water penetrating the test log and the shiitake mycelium and mold grown in the test log could be identified (Ogawa and Yashima 2020).

The origin of the NMR signal that reconstructs the MR image is the hydrogen atoms in water molecules. The NMR signal emitted from the hydrogen atoms contained in the many water molecules constituting wood tissue such as cellulose or hemicellulose cannot be measured under the MRI measurement condition of echo time $T E=12 \mathrm{~ms}$ since the $T_{2}$ relaxation time constant of the hydrogen atoms is much shorter than 1 ms (Müller et al. 2001; Gezici-Koç et al. 2017; Cai et al. 2020; Hiltunen et al. 2020). However, if wood contains liquid water, the water inside the wood can be visualized by MRI (Hall and Rajanayagam 1986; Chang et al. 1989; Wang and Joseph 1989; Bucur 2003; Kuroda et al. 2006; Hameury and Sterley 2006; Zhou et. al 2018; Hiltunen et. al. 2020).

\section{Identification method of fungi growth area by MRI}

Water molecules existing in wood that is adequately supplied with liquid water are roughly classified into two types: "bound water" and "free water" (Brownstein 1980; Gezici-Koç et al. 2017; Cai et al. 2020; Hiltunen et al. 2020). Since bound water is 
Table 2 Measurement parameters derived from simple spin echo and $T_{1}$ weighted images obtained from MRI measurement

\begin{tabular}{llllllll}
\hline Sequence & Characteristics & Slice plane & Pixel size & $T R[\mathrm{~ms}]$ & $T E[\mathrm{~ms}]$ & tpre $[\mathrm{ms}]$ & $\begin{array}{c}\text { Number } \\
\text { of slices }\end{array}$ \\
\hline (a) & High resolution & Vertical, xy & $128 \times 256$ & 1000 & 18 & No-pulse & 13 \\
(b) & High sensitivity & Vertical, xy & $128 \times 64$ & 1500 & 12 & No-pulse & 13 \\
(c) & $T_{1}$ weighted & Vertical, xy & $128 \times 64$ & 1500 & 12 & $20,30,40,50$, & 13 \\
& & & & & $60,80,110$, \\
(d) & High sensitivity & Horizontal, xz & $128 \times 64$ & 1500 & 12 & No-pulse & 16 \\
(e) & High resolution & Horizontal, xz & $256 \times 256$ & 1000 & 18 & No-pulse & 16 \\
\hline
\end{tabular}

tightly bound to molecules in the cell walls and fibers composed of mainly cellulose, hemicellulose and lignin, the $T_{2}$ relaxation time constant of the hydrogen atoms in the bound water is shorter than 1 ms (Müller et al. 2001; Gezici-Koç et al. 2017; Cai et al. 2020; Hiltunen et al. 2020). On the other hand, since free water existing in the voids such as cell lumens and vessels can move relatively freely, the $T_{2}$ relaxation time constant of free water is longer than $1 \mathrm{~ms}$. The water in wood can be visualized by MRI with the spin echo image sequence using a long $T E$ of $12 \mathrm{~ms}$ for free water.

Since the water content, $\beta$, of a cultivation $\log$ growing shiitake mycelium and mold is in the range of 30-60\% (Arima 1999), which is higher than the water content at the fiber saturation point (FSP), whose value is about 20-30\% (Nakada 2014), the free water existing in a shiitake cultivation log can be visualized by MRI. In addition, there have been some reports on spatial distributions of free water produced by decay fungus decomposing the cell walls of wood being measured by MRI (Pearce et al. 1994, 1997; Barry et al. 2001; Müller et al. 2001; Hiltunen et al. 2020).

In the case of logs with water content exceeding the water content of the FSP, shiitake mycelium and mold cannot be identified from the MR image because the NMR signal emitted from the free water existing in the shiitake mycelium and mold is much weaker than the NMR signal emitted from the free water existing in the test $\log$. Therefore, the test $\log$ was slowly dried to reduce the water content of the log to about $20 \%$, which is equal to or lower than the water content of FSP. As a result, water molecules existing in the test log could not be visualized in the MR image, and an MR image composed of only NMR signals from the free water existing in the shiitake mycelium and the mold could be obtained (Ogawa and Yashima 2020). Even if the water content of the test log is reduced to $20 \%$ or less by drying, the shiitake mycelia and molds are not killed. When liquid water is supplied to the dried test $\log$, the shiitake mycelium and mold begin to grow again.

\section{Diffusion equation describing liquid water penetrating wood}

A method of expressing the phenomenon of liquid water penetrating wood by an effective diffusion coefficient, $D_{\text {eff }}$, is generally used (Burr and Stamm 1956; Kumaran 1999; Candanedo and Derome 2005; Khazaei 2008; Gezici-Koç et. al. 
2017; Hunter 1993; Noorolahi et. al. 2008; Okoh 2014; Zhou et. al 2018). This method is based on Fick's diffusion law in order to quantitatively express the transport property of liquid water penetrating wood. When water permeation into the entire wood is viewed macroscopically, the effective diffusion coefficient is the most simplified index of the water penetration phenomenon and has the great advantage of being very easy to understand. The effective diffusion coefficient is very useful because much data have been accumulated by many studies and can be used to estimate the amount of water permeation into the wood. In this study as well, the effective diffusion coefficient of liquid water was calculated using the conventional method.

Assuming that liquid water is supplied from the whole bottom surface of the test $\log$ and water diffuses in only the $y$-axis direction with uniform water concentration at the $x z$ cross section, the water concentration distribution, $\rho_{\mathrm{H} 2 \mathrm{O}}(y, t)\left[\mathrm{kg} / \mathrm{m}^{3}\right]$, can be expressed by the unsteady one-dimensional diffusion equation as follows:

$$
\frac{\partial \rho_{\mathrm{H} 2 \mathrm{O}}(y, t)}{\partial t}=\frac{\partial}{\partial y}\left\{D_{\mathrm{eff}} \frac{\partial \rho_{\mathrm{H} 2 \mathrm{O}}(y, t)}{\partial y}\right\}
$$

where $D_{\text {eff }}\left[\mathrm{m}^{2} / \mathrm{s}\right]$ is the effective diffusion coefficient of liquid water penetrating a test log, $t[\mathrm{~s}]$ is time, and $y[\mathrm{~m}]$ is position. Given the boundary conditions, the exact solution of Eq. (2) can be obtained (see Appendix in Supplementary Material).

As an example, the time change of the normalized exact solution, $\bar{\rho}_{\mathrm{H} 2 \mathrm{O}}(y, t)$, when $D_{\text {eff }}$ is $5 \times 10^{-9} \mathrm{~m}^{2} / \mathrm{s}$, is shown in Fig. 2 a. From the figure, it can be seen that liquid water permeates in the $y$ direction with the passage of time, $t$.

The relationship between the water uptake mass, $d M_{\mathrm{H} 2 \mathrm{O}}(t)$, and cumulative water supply time, $t$, can be obtained as shown in the following equation (see Appendix in Supplementary Material):

$$
\frac{d M_{\mathrm{H} 2 \mathrm{O}}(t)}{A}=\frac{2 \rho_{\mathrm{H} 2 \mathrm{O}}(y=0) \sqrt{D_{\text {eff }}}}{\sqrt{\pi}} \sqrt{t}
$$

where $A\left[\mathrm{~m}^{2}\right]$ is the area of the bottom surface of the test log. This relationship is illustrated by the straight line in Fig. $2 \mathrm{~b}$. The gradient of the straight line, $\alpha\left[\mathrm{kg} / \mathrm{m}^{2}\right.$ $\mathrm{s}^{0.5}$ ], in Fig. $2 \mathrm{~b}$ is defined by the following equation:

$$
\alpha=\frac{2 \rho_{\mathrm{H} 2 \mathrm{O}}(y=0) \sqrt{D_{\text {eff }}}}{\sqrt{\pi}}
$$

From Eq. (4), $D_{\text {eff }}$ can be obtained from the equation below:

$$
D_{\text {eff }}=\frac{\pi}{4}\left\{\frac{\alpha}{\rho_{\mathrm{H} 2 \mathrm{O}}(y=0)}\right\}^{2}
$$

Equation (5) is the same as the equation shown in previous papers (Krus and Kunzel 1993; Kumaran 1999). Based on Eq. (5), if the water uptake mass, $d M_{\mathrm{H} 2 \mathrm{O}}(t)$, 
absorbed by the test log can be measured together with the cumulative water supply time, $t$, in the water uptake experiment, the gradient $\alpha$ can be obtained.

\section{Observation with optical microscope of liquid water penetrating the log disk}

To clarify the mechanism of liquid water permeation in the longitudinal direction of the log, an optical microscope was used for observation. The log was cut into a thin disk shape on the $x z$ cross section, liquid water was supplied to the bottom of the log disk, and it was observed how liquid water came out from the top surface of the log disk.

Figure 3a shows a photograph of sample $E$ in which the cut surface of the log disk has been flattened with a sharp cutter. The outer diameter of sample E was $38-42 \mathrm{~mm}$, and the thickness was $4 \mathrm{~mm}$. Water content of the $\log$ disk, $\beta_{\text {Mass}}$, before liquid water supply was about $14 \%$.

The arrangement of the log disk, water storage, and microscope is shown in Fig. 4. The log disk was put on two supports in the water reservoir, and the top surface of the log disk was photographed with an USB-optical-microscope (SANWA SUPPLY INC. USB-Microscope, 400-CAM058). The water reservoir was filled with liquid water, and the time when the bottom surface of the log disk was covered with liquid water was set as the water supply time $t=0$. The log disk was fixed to the supports so that it would not float in water.

\section{Results and discussion}

\section{Shiitake mycelium or mold grown on test log}

A typical photograph of the bottom surface of a test log (sample A) before the water uptake experiment (Dry \#1) is shown in Fig. 5a. A typical photograph in Fig. 5b shows that when the shiitake mycelium grows, the bottom surface of the test log is covered with the shiitake mycelium and turns white. A micrograph of the shiitake

(a)

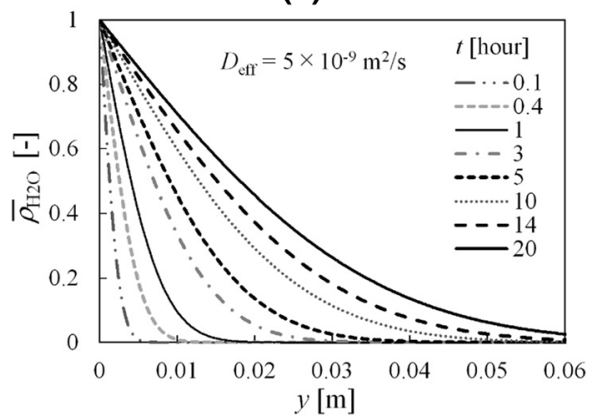

(b)

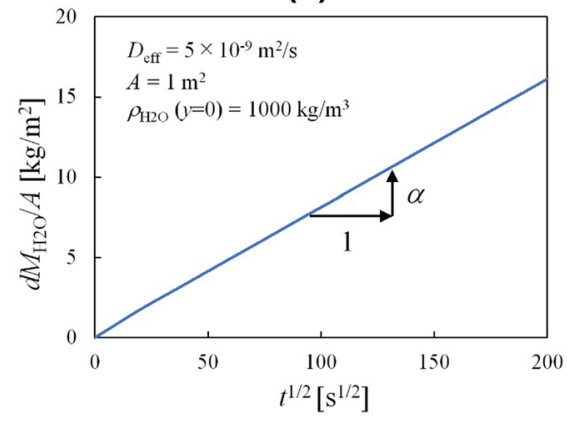

Fig. 2 a Time change of the normalized exact solution, $\bar{\rho}_{\mathrm{H} 2 \mathrm{O}}(y, t)$, in case of $D_{\text {eff }}=5 \times 10^{-9} \mathrm{~m}^{2} / \mathrm{s}$, b the relationship between $d M_{\mathrm{H} 2 \mathrm{O}}(t) / \mathrm{A}$ and $\sqrt{t}$ in case of $D_{\text {eff }}=5 \times 10^{-9} \mathrm{~m}^{2} / \mathrm{s}$ 
(a)

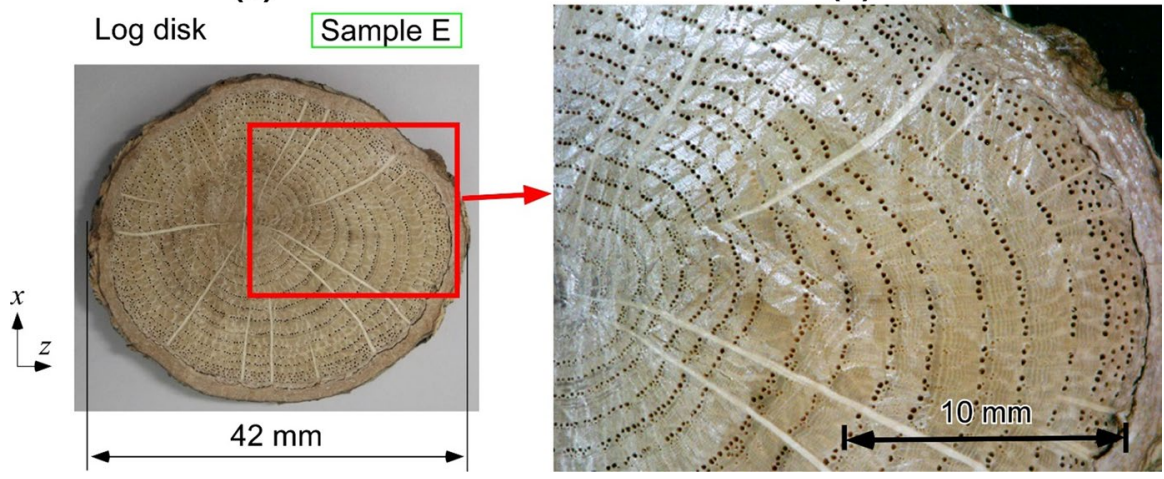

Fig. 3 Photographs of sample E showing the cut surface of the log disk, a Photograph of the whole cross-sectional surface, $\mathbf{b}$ enlarged photograph of the inside of the rectangle frame in Fig. (a)

Fig. 4 Arrangement of the $\log$ disk, water reservoir and microscope for observation of liquid water penetrating the log disk

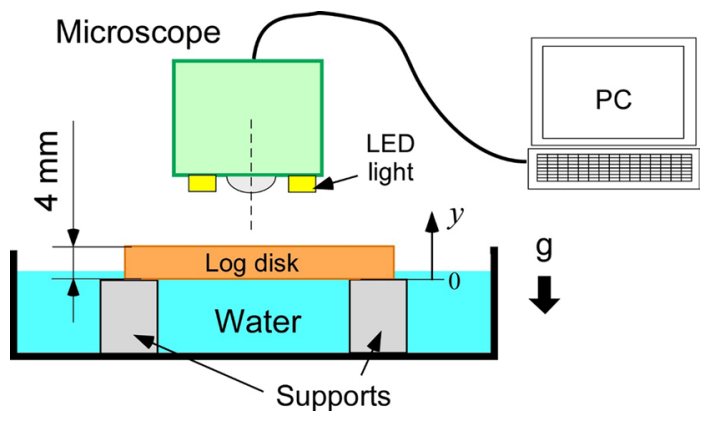

mycelium shown in Fig. 5b observed with an optical microscope is shown in Fig. 5f. Shiitake mycelium is cotton-like. Since the shiitake mycelia that cover the whole bottom surface of the test log strongly repel liquid water, even if the bottom surface of the test log is submerged in the water reservoir, only a small amount of liquid water can permeate the log. Therefore, just before the water uptake experiment (mycelium), the shiitake mycelium covering the bottom surface of the test log was scraped off with a plastic spatula. A photograph of the bottom surface from which the shiitake mycelium has been scraped off is shown in Fig. 5c, and a micrograph of the bottom surface of the test log is shown in Fig. $5 \mathrm{~g}$. These photographs show that the cotton-like shiitake mycelia disappear from the bottom surface, but some mycelia remain in the recesses. In this case, liquid water penetrates the test log.

On the other hand, as control samples, three test logs (Samples D, E, F) not inoculated with shiitake mycelium were also prepared. The first water uptake experiment (Dry \#1) was carried out using test logs dried indoors, and then the test logs were placed in an acrylic folder and deposited in the constant temperature incubator (temperature $21^{\circ} \mathrm{C}$, humidity $75 \%$ ) for $22-75$ days without drying 


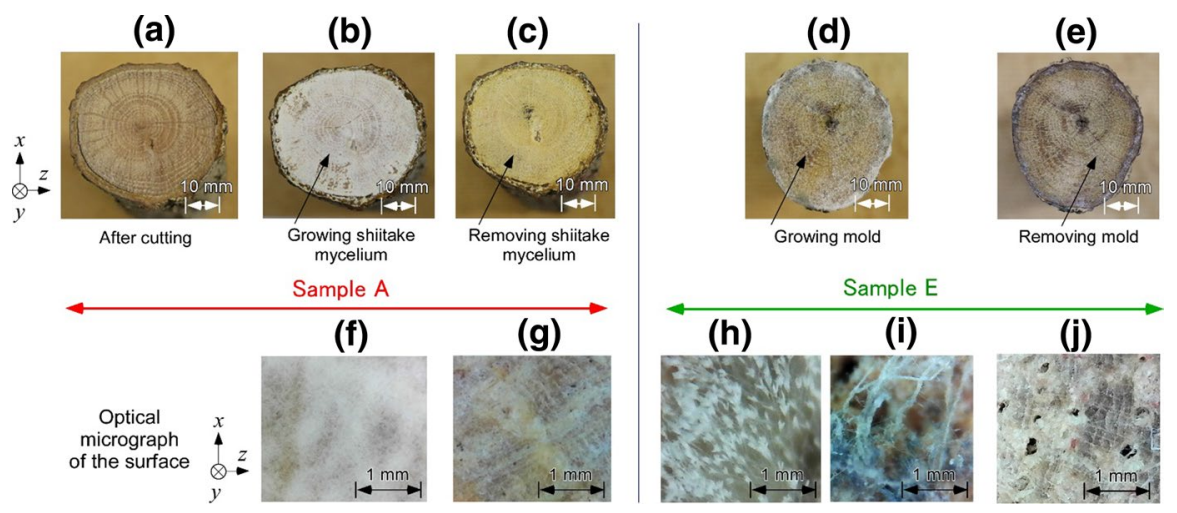

Fig. 5 Typical photographs of the bottom surfaces of the test logs (sample A and D); a before the water uptake experiment (Dry \#1), b shiitake mycelium grown for 68 days, $\mathbf{c}$ after shiitake mycelia have been scraped off, $\mathbf{d}$ mold generated for 24 days, $\mathbf{e}$ after mold has been scraped off, $\mathbf{f}$ cotton-like shiitake mycelium, $\mathbf{g}$ after shiitake mycelium has been scraped off, $\mathbf{h}$ a type of mold, $\mathbf{i}$ another type of mold, $\mathbf{j}$ after mold has been scraped off

the test $\log$. If a test $\log$ is not inoculated, mold will grow naturally. Mold was generated on the bottom surfaces of all test logs (samples D, E, F). A typical photograph of the bottom surface of a test log (sample E) with mold is shown in Fig. 5d, and optical micrographs of mold generated on the test log surface are shown in Fig. 5h and i. White mold is observed in Fig. 5h, and green mold is observed in Fig. 5i. The molds generated on the test logs were always the same. It is presumed that mold spores contained in the air adhered to the test logs and the molds generated on the test logs. In this study, the mold types were not identified. Just before the water uptake experiment (mold), the mold generated on the bottom surface of the test log was scraped off with a plastic spatula. A photograph of the bottom surface of the test log after the mold had been scraped off is shown in Fig. 5e, and a micrograph of the bottom surface is shown in Fig. 5j.

This experiment did not control the mold that grows on test logs. There are two reasons for this.

1. The test log was not sterilized to maintain the chemical composition, geometry and wettability of the original test log. The test log was exposed to air when it was dried indoors after logging. Since mold spores are contained in the air, mold adheres to the $\log$ when the test $\log$ is dried. Therefore, to kill the mold in the log, it is necessary to sterilize it with steam at $121{ }^{\circ} \mathrm{C}$ for $2 \mathrm{~h}$ or with ethylene oxide gas. However, it was feared that the sterilization process would change the water content, chemical composition and wettability of the test log, which could in turn change the water penetration into the test log. Consequently, the test log was not sterilized. In addition, the test log was not placed in a sterile room because the log already had mold spores attached to it.

2. Since shiitake mushrooms are cultivated outdoors and mold grows in a log, it is important for water to penetrate the $\log$ in which mold grows. In outdoor cultiva- 
tion of shiitake mushrooms, mold grows on the logs. What was important for us was understanding whether there is a difference in water absorption mass between the logs in which shiitake mycelium grows and the logs in which other types of fungi (molds) grow.

The growth of shiitake mycelium and mold in vessels of test logs was observed with an optical microscope (SANWA SUPPLY INC. 400-CAM058). The crosssectional surface of the test log was flattened by thinly scraping the surface of the test $\log$ with a sharp cutter. Figure $6 a$ and $b$ shows micrographs of the vessels of two test log. From Fig. 6a, it can be recognized that a large number of shiitake mycelia grow inside the vessels in both earlywood and latewood regions. On the other hand, in Fig. 6b, a slight amount of mold can be seen inside the vessels in only the earlywood region, but the density of mold is very low compared to the density of shiitake mycelia. From this, it is thought that when the mold growth period is short as in this experiment, the effect of mold growth on the results of the water uptake experiment is small.

\section{Identification of fungi growth area by MRI}

After reducing the water content of the test logs (samples A and D) to $20 \%$ or less, the obtained MR images of shiitake mycelium and mold and $T_{1}$ maps calculated from $T_{1}$-weighted images of the test logs are shown in Fig. 7. The two MR images of the $x z$ cross section in column (d) were measured at the positions of the two solid lines shown in the MR image in column (b).

From the MR images (a), (b), and (d) in row (i) of the figure, a gray area with a weak signal can be recognized in the test $\log$ (sample A). The $T_{1}$ relaxation time constant in this region was $200 \mathrm{~ms}$ or more. From the results of previous studies, it can be deduced that shiitake mycelium grows in this region with weak signal intensity

(a)

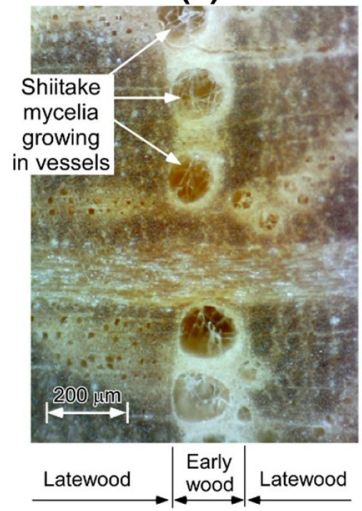

(b)

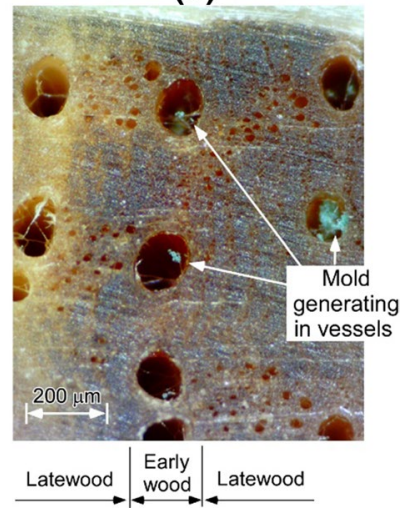

Fig. 6 a Micrograph of the vessels of the test log in which shiitake mycelia grow, b micrograph of the vessels of the test log in which mold is generated 


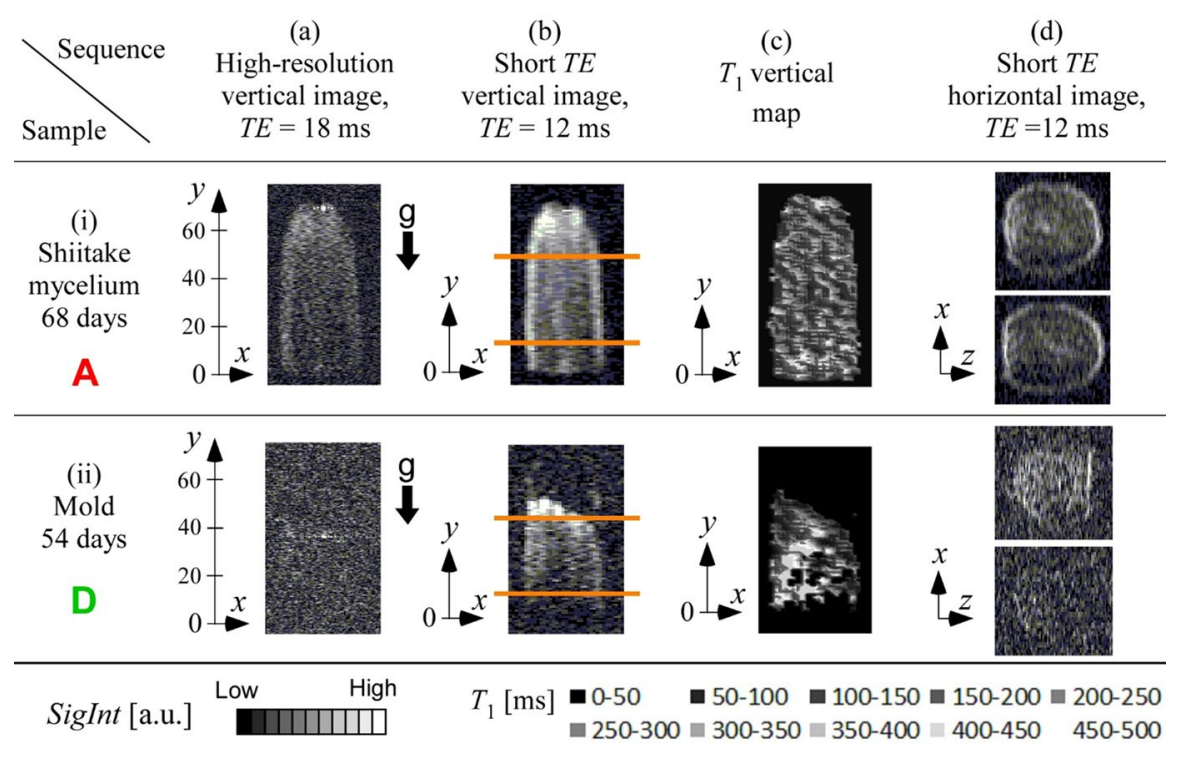

Fig. 7 MR images of shiitake mycelium and mold generated in the test logs (samples A and D) measured by sequences (a), (b) and (d), and $T_{1}$ maps calculated from $T_{1}$-weighted images measured by sequence (c)

and long $T_{1}$ relaxation time constant (Ogawa and Yashima 2020). It was found that the shiitake mycelium extended in the test log from the bottom surface $y=0 \mathrm{~mm}$ to the tip position $y=71 \mathrm{~mm}$. The tip positions of shiitake mycelium grown in the other two test logs (samples B and C) were $64 \mathrm{~mm}$ and $63 \mathrm{~mm}$, respectively.

In row (ii) in the figure, a clear gray region in the test log (sample D) cannot be recognized in the MR image (a), but the clear gray region can be recognized in the MR image (b). The $T_{1}$ relaxation time constant in this region was $200 \mathrm{~ms}$ or more. From the results of previous studies, it can be deduced that mold generates in this region (Ogawa and Yashima 2020). In the present measurements, the tip positions of mold grown in three test $\operatorname{logs}$ (samples D, E, and F) were $50 \mathrm{~mm}, 55 \mathrm{~mm}$, and $50 \mathrm{~mm}$, respectively.

\section{Water uptake mass of test log in which shiitake mycelium was grown}

To measure $d M_{\mathrm{H} 2 \mathrm{O}}(t)$ and $D_{\text {eff }}$ depending on the presence and absence of shiitake mycelium, first a water uptake experiment using dried test logs without shiitake mycelium (initial water content, $\beta_{\text {Mass }}$, was $11 \%$ ) was carried out. Then, a water uptake experiment using test logs in which shiitake mycelium grew was performed.

Figure 8a shows a graph where the mass of the test $\log$ (sample A), $M[\mathrm{~g}]$, is plotted against $t$. Three water uptake experiments were carried out in order from the top of Table 3. After the experiment (Dry \#1), the test logs were dried.

Two photographs of the bottom surface of the test log (sample C) are shown in Fig. 9. Figure 9a is a photograph before experiment (Dry \#1) and Fig. 9b is a 
(a)

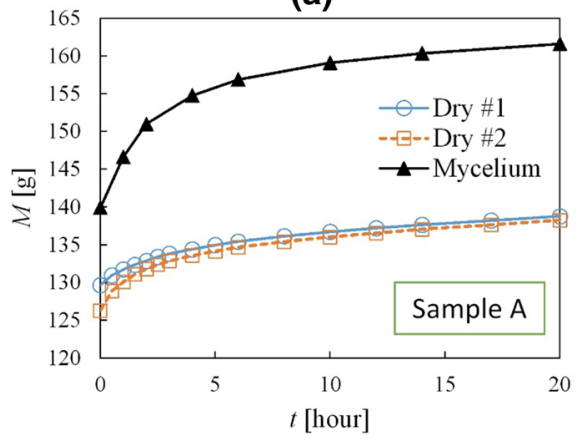

(b)

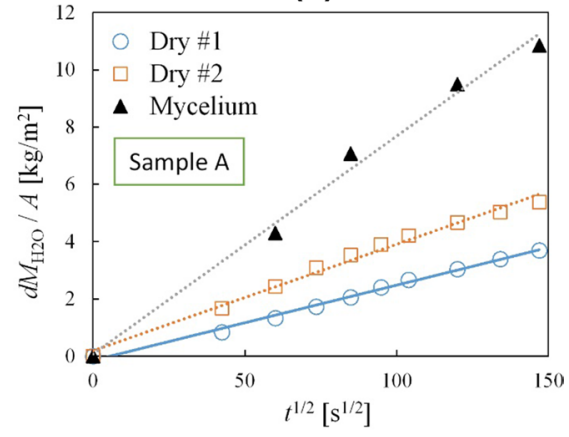

Fig. 8 a Mass of the test $\log$ (sample A), $M$, measured in the water uptake experiments (Dry \#1, \#2 and mycelium) vs $t$, b relationship between $d M_{\mathrm{H} 2 \mathrm{O}}(t) / \mathrm{A}$ and $\sqrt{t}$ obtained from Fig. 8(a)

photograph before experiment (Dry \#2). Figure 9b shows that the test log has many cracks, and that as the inside of the test log dried the cracks became deeper. As a result, the mass of test log became lighter due to drying after Dry \#1. Cracks occurred in all test logs as a result of drying after Dry \#1.

In the second water uptake experiment (Dry \#2), the mass of the test log (sample A) rapidly increased during the cumulative water supply time of $0-2 \mathrm{~h}$ because liquid water permeated into the test log by capillary force through some cracks occurring in the test $\log$. The mass of the test $\log , M(t=20 \mathrm{~h}$, Dry \#2) measured after $20 \mathrm{~h}$ during the second experiment (Dry \#2) was almost the same as the mass of the test $\log , M(t=20 \mathrm{~h}$, Dry \#1) measured during the first experiment (Dry \# 1). From this result, it can be said that the cracks in the test log increase the initial water uptake rate of the test log but have little effect on the final mass of the test log when liquid water has been supplied for $20 \mathrm{~h}$.

After the experiment (Dry \#2), shiitake mycelium was inoculated onto the bottom surface of the test log and grown for 68 days. During this period, the mass of the test $\log , M(t=0$, mycelium), before the water uptake experiment (Mycelium) increased slightly as shown in Table 3 . The water content of the test $\log , \beta_{\text {Mass }}$, is about $20 \%$.

The mass of the test $\log , M$ ( $t$, mycelium), is indicated in Fig. 8a. It can be seen that the mass of the test log measured in the experiment (Mycelium) increased rapidly in a shorter time than that measured during the experiments (Dry \#1 and \#2).

Based on the water uptake mass, $d M_{\mathrm{H} 2 \mathrm{O}}(t=20 \mathrm{~h}$, Dry \#1 and \#2), measured in the experiments (Dry \#1 and \#2), the enhanced coefficient, $\gamma[-]$, of the water uptake mass of the $\log , d M_{\mathrm{H} 2 \mathrm{O}}(t=20 \mathrm{~h}$, Mycelium), in which the shiitake mycelium grew measured during the experiment (Mycelium) was calculated by the following equation:

$$
\gamma=\frac{d M_{\mathrm{H} 2 \mathrm{O}}(t=20 \text { hours, Mycelium })}{d M_{\mathrm{H} 2 \mathrm{O}}(t=20 \text { hours, Dry \#1 and \#2) }}
$$

The enhanced coefficient of $d M_{\mathrm{H} 2 \mathrm{O}}, \gamma$, for three test logs (samples $\mathrm{A}, \mathrm{B}$, and $\mathrm{C}$ ) is shown in Table 3. Although the water content (about 20\%) of the test logs in which 
Table 3 Mass and water uptake mass of the test log (sample A) measured in three water uptake experiments (Dry \#1, \#2 and Mycelium), and the effective diffusion coefficient calculated from the water uptake mass

\begin{tabular}{|c|c|c|c|c|c|c|}
\hline $\begin{array}{l}\text { Experi- } \\
\text { ment \# }\end{array}$ & $M(t=0)[\mathrm{g}]$ & $\begin{array}{l}M(t=20 \mathrm{~h}) \\
{[\mathrm{g}]}\end{array}$ & $\begin{array}{l}d M_{\mathrm{H} 2 \mathrm{O}}(t=20 \mathrm{~h}) \\
{[\mathrm{g}]}\end{array}$ & $\begin{array}{l}\text { Enhanced } \\
\text { coefficient of } \\
d M_{\mathrm{H} 2 \mathrm{O}}, \gamma[-]\end{array}$ & $D_{\text {eff }}\left[\mathrm{m}^{2} / \mathrm{s}\right]$ & $\begin{array}{l}\text { Enhanced } \\
\text { coefficient of } \\
D_{\text {eff,, }} \varepsilon[-]\end{array}$ \\
\hline Dry \#1 & 129.65 & 138.78 & 9.13 & 1 & $3.97 \times 10^{-9}$ & 1 \\
\hline Dry \#2 & 126.26 & 138.26 & 12.00 & & $7.97 \times 10^{-9}$ & \\
\hline Mycelium & 139.91 & 161.61 & 21.70 & 2.05 & $14.5 \times 10^{-9}$ & 2.43 \\
\hline
\end{tabular}

(a)

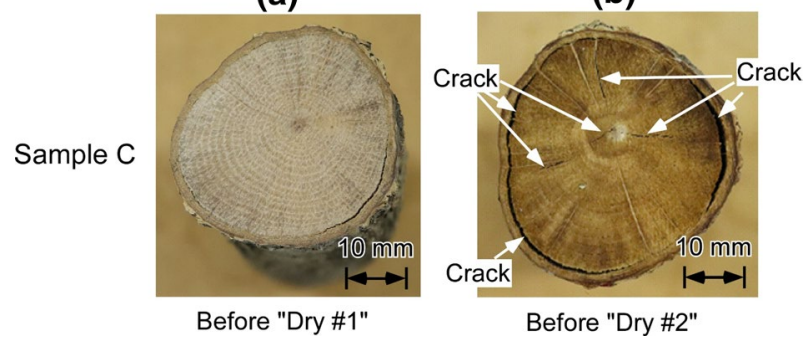

Fig. 9 Photographs of the bottom surface of the test $\log$ (sample C), a before experiment (Dry \#1), b before experiment (Dry \#2)

the shiitake mycelium grew was higher than the water content (11\%) of the dried test logs without shiitake mycelium, the water uptake mass of the test logs with shiitake mycelium was higher than that of the dried test logs without shiitake mycelium.

\section{Enhancement of effective diffusion coefficient by shiitake mycelium}

To calculate $D_{\text {eff }}$ of liquid water penetrating the test log (Sample A), the relationship between $d M_{\mathrm{H} 2 \mathrm{O}}(t) / \mathrm{A}$ and $\sqrt{t}$ was plotted as shown in Fig. $8 \mathrm{~b}$. It can be seen that the plots obtained for each experiment (Dry \#1, \#2 and mycelium) for a cumulative water supply time of $0-6 \mathrm{~h}$ can be approximated by three straight lines. At cumulative water supply times of $6 \mathrm{~h}$ or more, the points measured in the experiment (mycelium) were below the straight line. The reason why the water uptake mass decreases after $6 \mathrm{~h}$ is that the tip position of the water permeating into the test log in which shiitake mycelium was grown has reached the top of the growth region of the shiitake mycelium.

The values of $D_{\text {eff }}$ obtained by Eq. (5) are shown in Table 3. It can be seen that the $D_{\text {eff }}$ of the test log in which the shiitake mycelium grew is larger than the $D_{\text {eff }}$ of the dried log. Figure 10 shows the $D_{\text {eff }}$ measured in the three experiments (Dry \#1, \#2 and Mycelium) using bar graphs. From the three effective diffusion coefficients, 


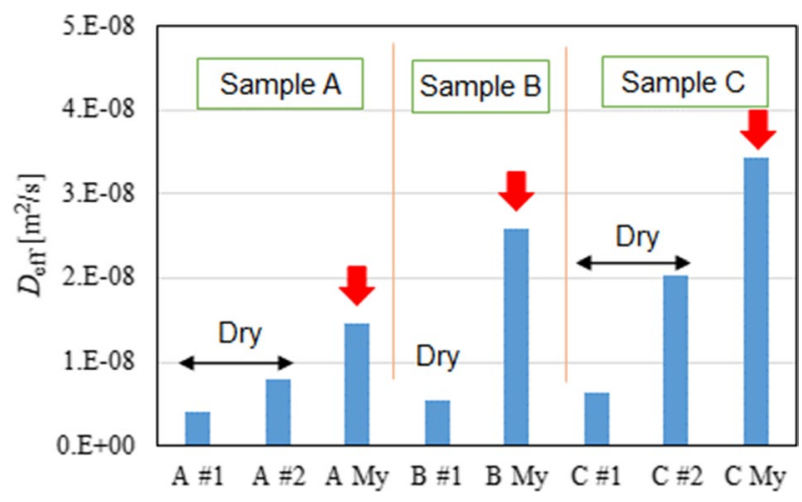

Fig. 10 Effective diffusion coefficients obtained from three test logs (samples A, B and C) in water uptake experiments (Dry \#1, \#2 and mycelium)

$D_{\text {eff }}$, obtained from the three test logs in which shiitake mycelium grew, it can be understood that they constitute the largest values among the same type of test logs.

Based on $D_{\text {eff }}$ (average value of Dry \#1 and \#2), the enhanced coefficient, $\varepsilon[-]$, of the effective diffusion coefficient of the test $\log , D_{\text {eff }}$ (mycelium), was calculated by the following equation:

$$
\epsilon=\frac{D_{\text {eff }}(\text { Mycelium })}{D_{\text {eff }}(\text { average value of Dry \#1 and \#2) }}
$$

The enhanced coefficient of $D_{\text {eff }}, \varepsilon$, at three test logs (sample A, B and C) is shown in Table 3.

\section{Water uptake mass of test log in which mold was generated}

Water uptake experiments (Dry \#1 and Mold) were carried out by the same procedure as above using three test logs (sample D, E, and F) as control samples not inoculated with shiitake mycelium.

Figure 11a shows $M$ measured in the first water uptake experiment (Dry \#1) using the test log (sample D) plotted against $t$. The measured values are shown in Table 4.

The mass of the test log in which mold was generated, $M(t=0$, Mold), of the water uptake experiment (mold) before liquid water supply was almost the same as the mass of the test $\log$ without mold, $M(t=20 \mathrm{~h}$, Dry \#1), in the water uptake experiment (Dry \#1) after liquid water supply for $20 \mathrm{~h}$. The mass of the test log measured in the water uptake experiment (Mold) is shown in Fig. 11a and in Table 4. The water uptake mass, $d M_{\mathrm{H} 2 \mathrm{O}}(t=20 \mathrm{~h}$, Mold), was reduced to about half of the $d M_{\mathrm{H} 2 \mathrm{O}}(t=20 \mathrm{~h}$, Dry \#1). It is thought that there are two reasons why the water uptake mass of the test log in which mold generated decreased. 
(a)

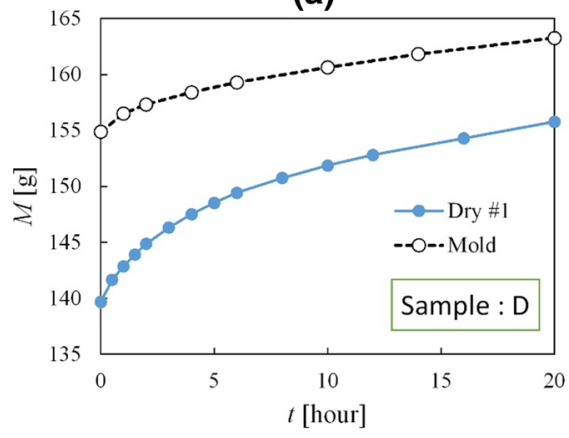

(b)

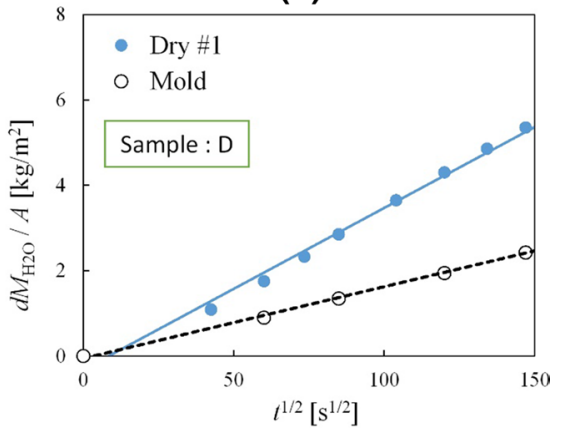

Fig. 11 a Mass, $M$, measured in the water uptake experiments (Dry \#1 and Mold) using (sample D) vs $t$, b relationship between $d M_{\mathrm{H} 2 \mathrm{O}}(t) / \mathrm{A}$ and $\sqrt{t}$ obtained from plots of Fig. (a)

Table 4 Mass and water uptake mass of the test log (sample D) measured in two water uptake experiments (Dry \#1 and mold), and effective diffusion coefficient calculated from the water uptake mass

\begin{tabular}{lllllll}
\hline $\begin{array}{l}\text { Experi- } \\
\text { ment \# }\end{array}$ & $M(t=0)[\mathrm{g}]$ & $\begin{array}{l}M(t=20 \mathrm{~h}) \\
{[\mathrm{g}]}\end{array}$ & $\begin{array}{l}d M_{\mathrm{H} 2 \mathrm{O}}(t=20 \mathrm{~h}) \\
{[\mathrm{g}]}\end{array}$ & $\begin{array}{l}\text { Enhanced } \\
\text { coefficient of } \\
d M_{\mathrm{H} 2 \mathrm{O},} \gamma[-]\end{array}$ & $D_{\text {eff }}\left[\mathrm{m}^{2} / \mathrm{s}\right]$ & $\begin{array}{l}\text { Enhanced } \\
\text { coefficient of } \\
D_{\text {eff,, }} \varepsilon[-]\end{array}$ \\
\hline Dry \#1 & 139.67 & 155.77 & 16.10 & 1 & $8.26 \times 10^{-9}$ & 1 \\
Mold & 154.87 & 163.26 & 8.39 & 0.52 & $0.67 \times 10^{-9}$ & 0.081 \\
\hline
\end{tabular}

1. The water content of the test log before the water uptake experiment (Mold) was about $20 \%$, and it was higher than that of the dried test log (initial water content was $11 \%$ ).

2. As shown in Fig. 6, the density of mold mycelium was smaller than that of shiitake mycelium, and the effect of diffusing water through the cell walls was small, so that it was difficult for liquid water to rise in the vessels by capillary force.

The enhanced coefficient $\gamma[-]$ of $d M_{\mathrm{H} 2 \mathrm{O}}(t=20 \mathrm{~h}$, mold $)$, of the test log in which mold generated was calculated. The value of $\gamma$ in the sample D was 0.52 . The values of $\gamma$ in the two samples $\mathrm{E}$ and $\mathrm{F}$ were 0.43 and 0.51 , respectively. It can be said that the decrease in the water uptake mass of the test log measured in the water uptake experiments (Dry \#1 and Mold) is reproducible.

\section{Enhancement of effective diffusion coefficient by mold}

To calculate the effective diffusion coefficient, $D_{\text {eff }}$, of liquid water penetrating the test $\log$ (sample D), the relationship between the water uptake mass per unit area, $d M_{\mathrm{H} 2 \mathrm{O}}(t) / \mathrm{A}$, and the square root of the cumulative water supply time, $\sqrt{t}$, are shown in Fig. 11b. The values of $D_{\text {eff }}$ obtained with sample D are shown in Table 4. Figure 12 shows the $D_{\text {eff }}$ measured in the two experiments (Dry \#1 and mold) with 


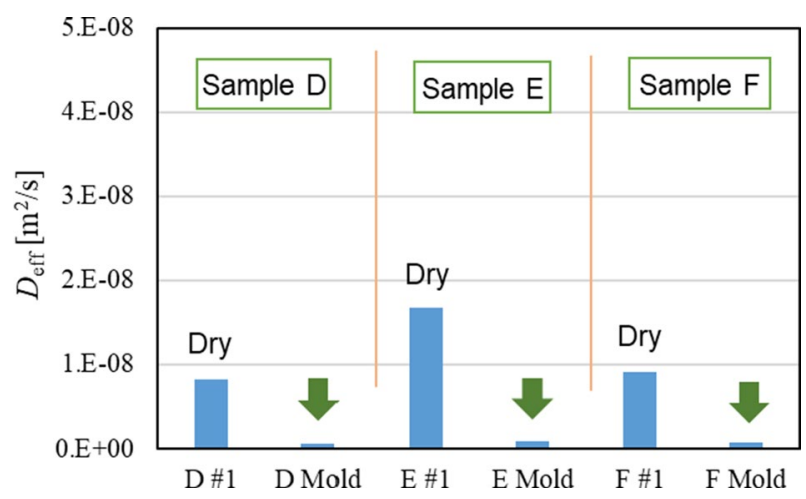

Fig. 12 Effective diffusion coefficients, $D_{\text {eff }}$, obtained from three test logs (samples D, E and F) in two water uptake experiments (Dry \#1 and mold)

three test logs (samples D, E and F). The $D_{\text {eff }}$ obtained from the three test logs in which mold generated are less than 10 times smaller than that for the dried test logs.

Based on the $D_{\text {eff }}$ obtained in the water uptake experiments (Dry \#1), the enhanced coefficient, $\varepsilon$ [-], of $D_{\text {eff }}$ (mold) was calculated. The value of $\varepsilon$ obtained by the test $\operatorname{logs}$ (sample D) is shown in Table 4 . Three values of $\varepsilon$ obtained by three test logs (sample D, E and F) were less than 0.1.

\section{Comparison of enhanced coefficient by shiitake mycelium and mold}

To compare the increase/decrease in water uptake mass and effective diffusion coefficient due to shiitake mycelium or mold, $\gamma$ and $\varepsilon$ in six test $\log$ (sample A-F) in which shiitake mycelium or mold grew are shown in Fig. 13a and b, respectively. Both values in the test logs in which shiitake mycelium grew exceed 1, indicating enhancement. In contrast, both values in the test logs with mold are less than 0.6, representing decrease. In addition, it is found from comparison of Fig. 13a and b that $\varepsilon$ evaluates water penetration into the test $\log$ more sensitively than $\gamma$.

\section{MR images of water rising in test log}

MRI was used to measure the internal spatial distribution of water rising in the test $\log$ without having to cut the log. MR images of the water penetration process into the test log without fungi is shown in order to discuss the mechanism by which liquid water rises in the longitudinal direction of the test log.

The dried test log (sample E, without shiitake mycelium or mold) was used. The test $\log$ was stored for 2 months in a constant temperature incubator at a temperature of $21{ }^{\circ} \mathrm{C}$ and humidity of $75 \%$. Water content of the test log was about $21 \%$. As shown in Fig. 1b, liquid water was supplied to the bottom surface of the test 
(a)

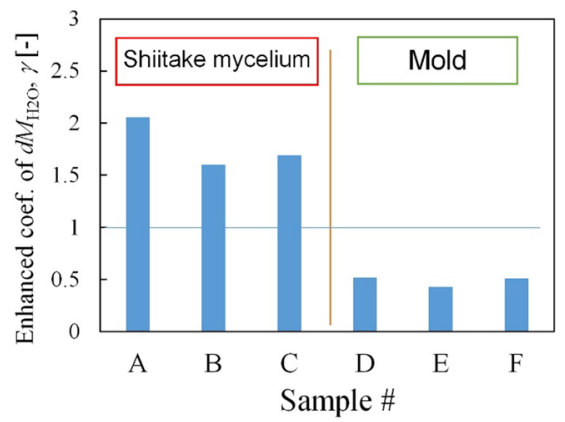

(b)

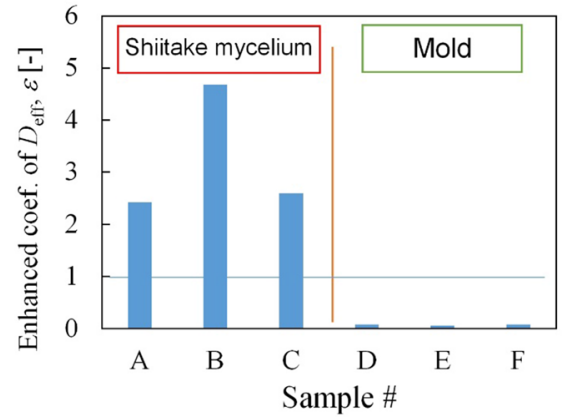

Fig. 13 Enhanced coefficient of water uptake mass, $\gamma$, and enhanced coefficients of effective diffusion coefficient, $\varepsilon$, in the test $\operatorname{logs}$ (sample A to F) in which shiitake mycelium/mold grew

$\log$. Afterward, the test log was taken out of the water reservoir, measured by MRI, and immersed again in the water reservoir. By repeating this procedure, the cumulative water supply time was obtained. MR images of $x y$ and $x z$ cross sections were obtained using the sequences (a) and (e) shown in Table 2, respectively. The slice thickness of the MR images was $3.8 \mathrm{~mm}$.

The acquisition times of the $x y$ image and $x z$ image were $8 \mathrm{~min}$ and $9 \mathrm{~min}$, respectively. The time required to place/remove the test $\log$ in the RF probe of the MRI measurement system and the time required for the MRI measurement was 30 min, during which no liquid water was supplied to the test log. MRI measurement was performed with a cumulative water supply time of $0.5,1,2,3,4,6,8,10,14$, and $20 \mathrm{~h}$ from the start of water supply. As will be described later, the liquid water that fills the vessels in the test log diffuses into the wood fibers via the vessel cells. The decrease in signal intensity of the MR image was in the range of 1 to $3 \%$ because of the diffusion of water during the $30 \mathrm{~min}$ when the liquid water supply was stopped. Since the signal decrease of the MR image was sufficiently small during the 30-min MRI measurement, it might be considered that the water diffusion occurring in the test log was stopped during the MRI measurement.

\section{MR images acquired at the time of liquid water supply}

In row (i) at the top of Fig. 14, MR images of the test log (water content of about $22 \%$ ) before liquid water supply are shown. Nothing is seen in the MR image other than noise. When the water content of the test log is less than the water content of the fiber saturation point (FSP), as described above, the $T_{2}$ relaxation time constant of the water permeates into the wood fibers, becoming as small as $1 \mathrm{~ms}$ or less (Müller et al. 2001; Gezici-Koç et al. 2017; Cai et al. 2020; Hiltunen et al. 2020), so the MR image acquired with echo time, $T E$, of $18 \mathrm{~ms}$ cannot visualize the water contained in the test log.

The MR images of the test log acquired with cumulative water supply time of $1 \mathrm{~h}$ are shown in row (ii) of Fig. 14. The position $y=0$ on the $y$-axis (the longitudinal 


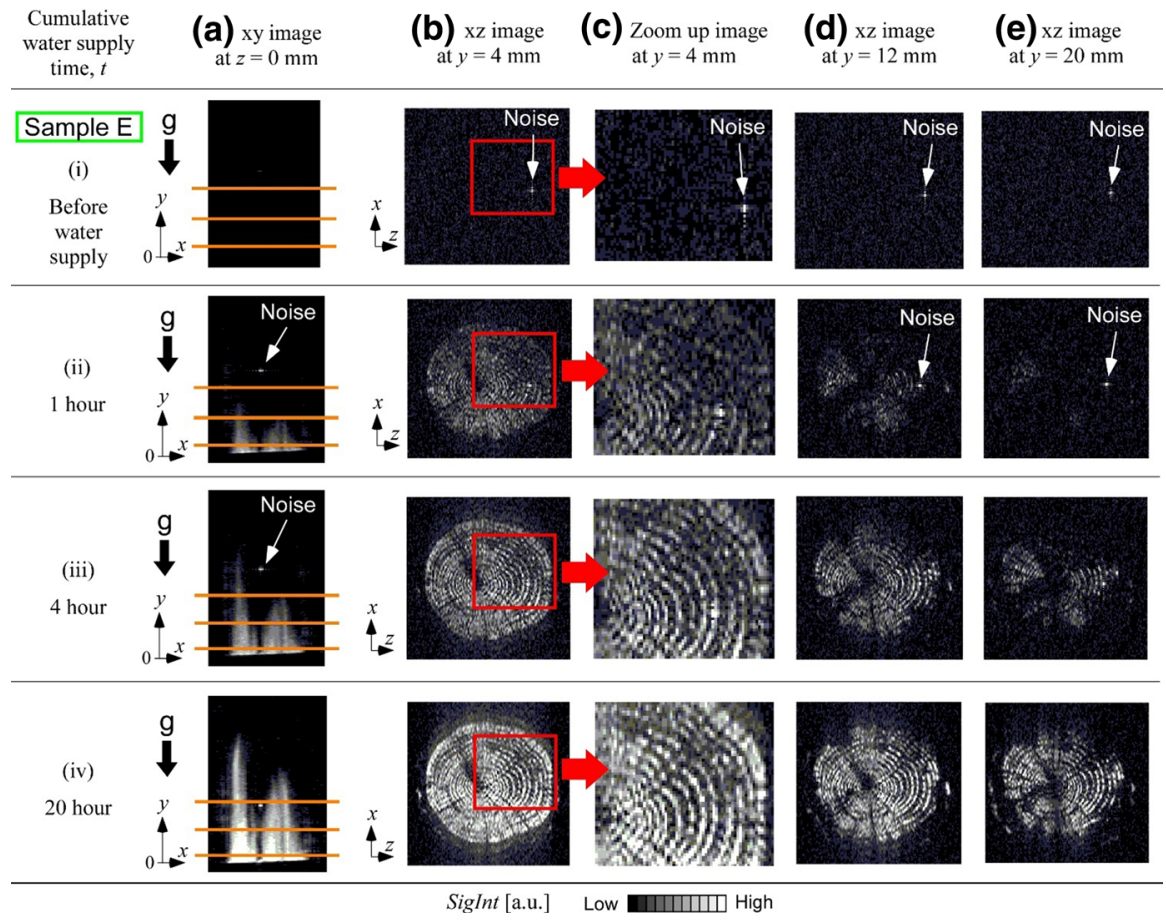

Fig. 14 MR images of $x y$ and $x z$ cross sections of sample E depending on the cumulative water supply time

direction) shown next to the MR image of the xy cross section in column (a) of Fig. 14 corresponds to the bottom surface of the test log. From the MR images shown in rows (ii) to (iv) of Fig. 14, it can be understood that water rises from the bottom surface of the test $\log$ in the $y$-axis direction as the cumulative water supply time becomes longer.

MRI images of the $x z$ cross sections at three positions $y=4,12,20 \mathrm{~mm}$ are shown in columns (b), (d), and (e) of Fig. 14, respectively. These three $y$ positions correspond to the positions of the three solid lines on the MR image shown in column (a). From the MR images of the $x z$ cross section in rows (ii) to (iv), water is seen to rise in the whole $x z$ cross section at the bottom surface of the test log, but water rises only partially toward the top of the test log. It can be seen that the pattern of the white dots in the zoomed-in images shown in column (c) is identical to the pattern of the vessels in earlywood regions, identified from the cross-sectional photograph of sample $\mathrm{E}$ as shown in Fig. 3b. The spatial resolution of the MR image of the $x z$ cross sections is $0.39 \mathrm{~mm} \times 0.39 \mathrm{~mm}$.

On the other hand, from the cross-sectional photograph of sample E shown in Fig. $3 \mathrm{~b}$, the maximum diameter of the vessel is about $0.2 \mathrm{~mm}$, the distance between the adjacent vessels is 0.2 to $0.4 \mathrm{~mm}$, and the interval between annual rings is 1.5-2 mm. From comparison of the spatial resolution of the MR image and the 
interval between the vessels, the individual vessels cannot be identified in the MR image, but it is possible to recognize the shape of the annual ring constituted from the vessels. From the zoomed-in image, it can be inferred that the shape of the annual ring in the MR image originates from the NMR signal emitted from the liquid water that fills the vessels. The shape of the annual ring can also be seen in the MR images in columns (d) and (e) measured at the upper positions $y=12$ and $20 \mathrm{~mm}$, and liquid water existing in the vessel is continuous in the $y$-axis direction. From the above observation results, it can be said that liquid water rises from the bottom surface through the vessels.

\section{MR images acquired after stopping liquid water supply}

The water-absorbed sample E described in the previous section was dried at room temperature, the test log was then turned over, and liquid water was then absorbed from the other end of the test log for $15 \mathrm{~h}$. The water absorption surface of the test $\log$ is thus redefined as the bottom of the test $\log$. The water uptake mass, $d M_{\mathrm{H} 2 \mathrm{O}}$ $(t=15 \mathrm{~h})$, absorbed into the test $\log$ in $15 \mathrm{~h}$ was $17.45 \mathrm{~g}$. The water supply to the test log was stopped (the elapsed time from water supply time was set to 0), and MR images of the test $\log$ were acquired at intervals of about $20 \mathrm{~min}$. Rows (i)-(iv) of Fig. 15 show MR images acquired with elapsed times, $t$, of 11-5785 min from stop of water supply.

The MR image after $11 \mathrm{~min}$ in row (i) of Fig. 15 shows that a very strong NMR signal is emitted from liquid water in vessels, and the vessels at the bottom of the $\log$ are filled with liquid water. As time passes, from row (i) to row (iv), the signal intensity of the MR image decreases. The signal intensity of the MR image after $t=5785$ min shown in row (iv) is very weak, and liquid water in vessels cannot be recognized from the MR images. The water uptake mass of the test log at the finish of the MRI measurement with an elapsed time $t=5790 \mathrm{~min}$ is $16.03 \mathrm{~g}$. The mass of water lost from the test log by drying during the MRI measurement is $1.42 \mathrm{~g}$, corresponding to $8.1 \%$ of the water uptake mass. The mass ratio of the lost water was sufficiently smaller than the reduction ratio of the signal intensity of the MR image, as described later.

\section{Decrease in signal intensity of MR images}

The $y$ (longitudinal) direction distribution of the signal intensity, $\operatorname{Sig} \operatorname{Int}(y, t)$, obtained by integrating the signal intensity of the MR image of the $x y$ cross section at the position $z=0$ shown in column (a) of Fig. 15 along the $x$ direction is presented in Fig. 16a. The signal intensity distributions have the maximum signal intensity at the bottom surface of the test $\log$ at position $y=0$, and decrease with increase in position $y$. In addition, the signal intensity distributions decrease significantly with increase in elapsed time, $t$, from stop of water supply. Figure $16 \mathrm{~b}$ demonstrates the time changes of the signal intensity distributions, $\operatorname{SigInt}(y, t)$, at the positions 


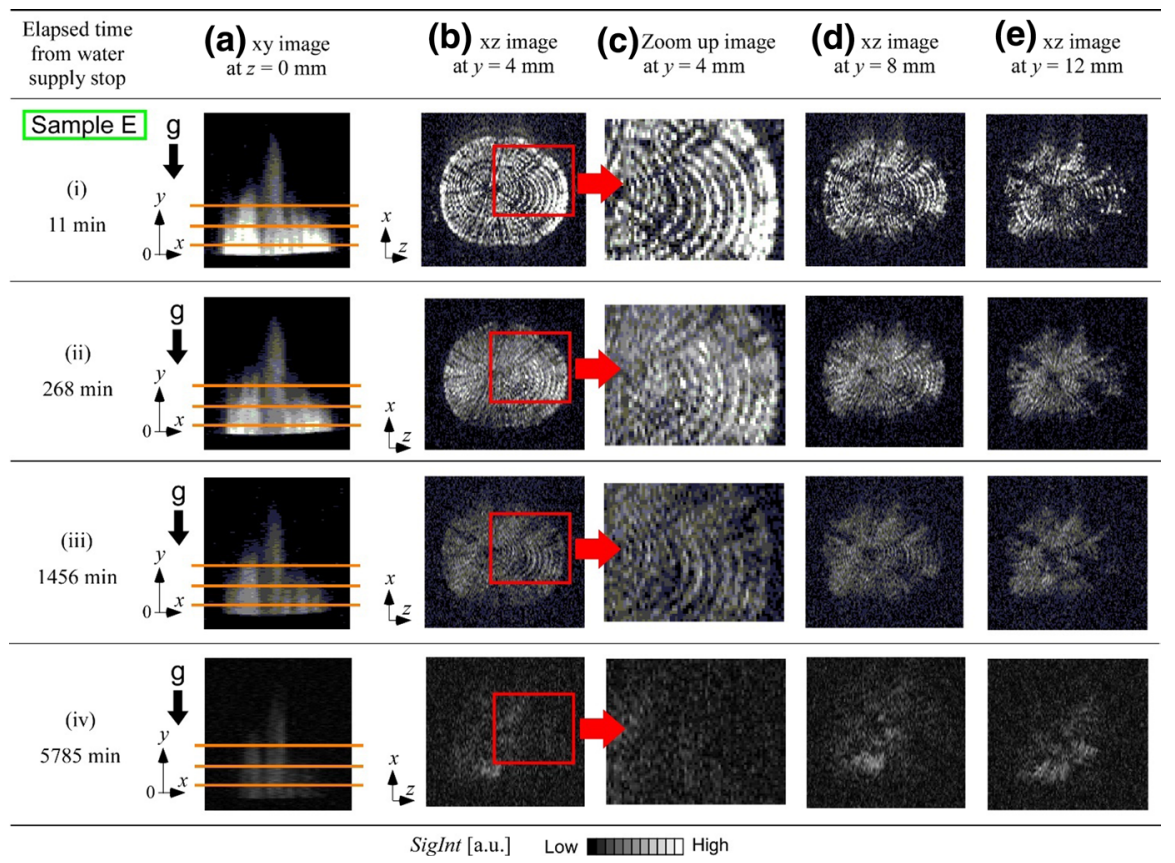

Fig. 15 MR images of $x y$ and $x z$ cross sections of sample E depending on the elapsed time from water supply stop

$y=1.6,5.7$, and $9.8 \mathrm{~mm}$. The corresponding three positions are indicated by arrows in Fig. 16a.

It can be seen from Fig. 16b that the signal intensity, $\operatorname{SigInt}(y, t)$, decreases substantially in a linear manner with time and decreases significantly stepwise after about $t=280 \mathrm{~min}$. After an elapsed time $t=300 \mathrm{~min}$, the signal intensity drops again in a linear way. This stepwise decrease was similarly measured in the same experiment with a different test log. It is thought the cause of the stepwise decrease in signal intensity is that liquid water in latewood vessels with diameter of 10-20 $\mu \mathrm{m}$ diffuses into the surrounding wood fibers and the amount of liquid water left in the latewood vessels almost disappears. On the other hand, the amount of liquid water in earlywood vessels with diameter of 100-200 $\mu \mathrm{m}$ is so large that it does not disappear for $300 \mathrm{~min}$, and liquid water thus remains in the earlywood vessels. The model of water transfer in wood projected based on these observation results is described later.

\section{Water content distribution measured by mass method}

After the MRI measurement shown in row (iv) of Fig. 15, the test log was cut with a band saw at 5-mm intervals along the $y$ (longitudinal) direction from the bottom of the test log to make twenty log disks. The mass, $m_{\text {wet }}(y)$, of the twenty log disks was measured using an electronic balance (SHIMADZU CORPORATION, TX2202N) 
(a)

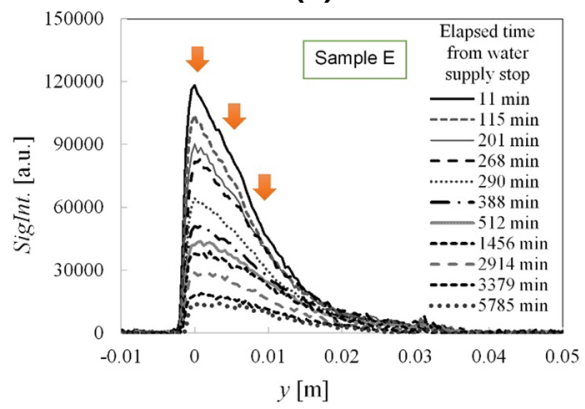

(b)

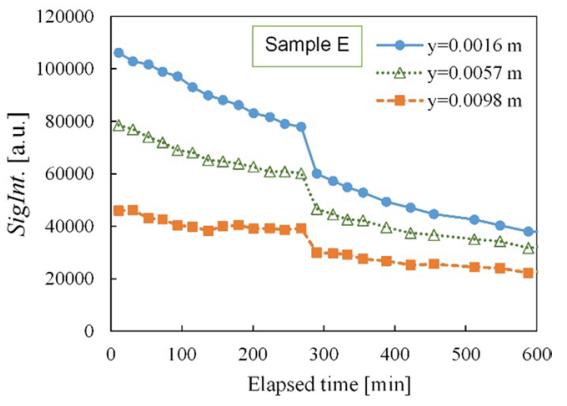

Fig. 16 a Time change in the $y$ (longitudinal) direction distribution of signal intensity, $\operatorname{Sig} \operatorname{Int}(y, t)$, obtained by integrating the signal intensity of the MR image of the $x y$ cross section at position $z=0$ along the $x$ direction, $\mathbf{b}$ time changes in the signal intensity distributions, $\operatorname{Sig} \operatorname{Int}(y, t)$, at the positions $y=1.6,5.7$, and $9.8 \mathrm{~mm}$ shown in $\mathbf{a}$

immediately after cutting. Then, all of the log disks were dried in a dryer $\left(102{ }^{\circ} \mathrm{C}\right.$, $24 \mathrm{~h}$ ), and the mass, $m_{\text {Dry }}(y)$, of the twenty dried log disks was measured. The $y$ (longitudinal) direction distribution of the water content, $\beta_{\text {Mass }}(y)$, of the test log was calculated from $m_{\text {wet }}(y)$ and $m_{\text {Dry }}(y)$ using Eq. (1). The $y$ (longitudinal) direction distribution of water content, $\beta_{\text {Mass }}(y)$, of test log (sample E) is shown in Fig. 17a. The water content, $\beta_{\text {Mass }}(y)$, reached the maximum value at the bottom of the test log and decreased sharply with increase in position $y$.

Figure $17 \mathrm{~b}$ shows the relationship between the signal intensity, $\operatorname{Sig} \operatorname{Int}(y$, $t=5785 \mathrm{~min}$ ), measured at the elapsed time $t=5785 \mathrm{~min}$ in Fig. 16a and the water content, $\beta_{\text {Mass }}(y)$, measured at the elapsed time of 5820 min in Fig. 17a at position $y$. From Fig. 17b, it can be seen that the signal intensity, SigInt, is almost zero when water content, $\beta_{\text {Mass }}$, is about $30 \%$ or less. Since the water content, $\beta_{\text {Mass }}$, in which free water appears in the test log corresponds to the water content of FSP and its value is estimated to be 25 to $30 \%$, it can be said that the MR images shown in Figs. 14 and 15 represent the spatial distributions of free water existing in the test log (Müller et al. 2001; Gezici-Koç et al. 2017; Cai et al. 2020; Hiltunen et al. 2020).

\section{Observation with optical microscope of liquid water penetrating the log disk}

The photograph of the top surface of the disk log (sample E) is shown in Fig. 18a. A large number of earlywood vessels (diameter of about $150 \mu \mathrm{m}$ ) and latewood vessels (diameter of 10-20 $\mu \mathrm{m}$ ) can be seen. As shown in Fig. 4, liquid water was supplied to the bottom surface of the log disk, and liquid water coming out from the top of the log disk was observed with the optical microscope. The elapsed time, $t$, indicates the time since liquid water touched the bottom surface of the log disk.

As shown in Fig. 18b, when the elapsed time, $t$, passed $13 \mathrm{~min}$, the area near some thin vessels in the latewood region, present in the circle, changes to a brown color from white. The change in color is caused by liquid water passing through the latewood vessels and reaching the upper surface of the log disk, wetting the surface 
(a)

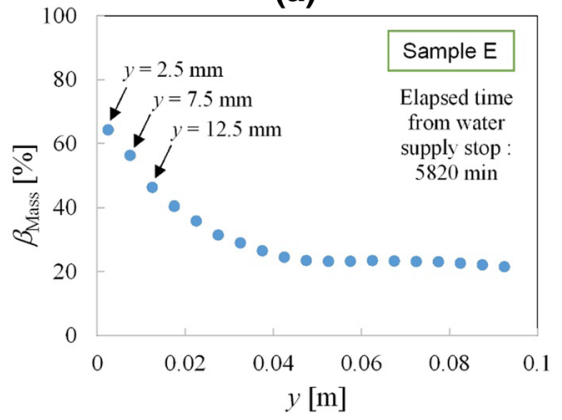

(b)

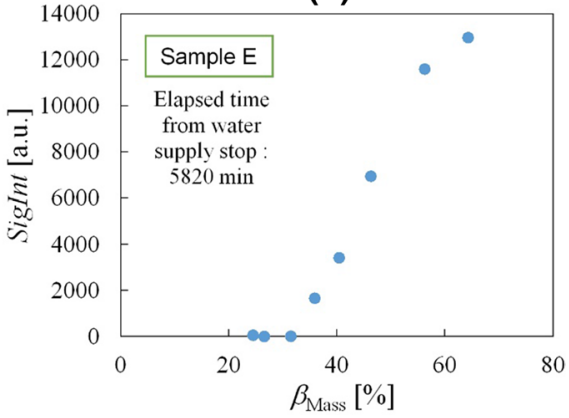

Fig. 17 a $y$ (longitudinal) direction distribution of water content, $\beta_{\text {Mass }}(y)$, of the test $\log$ measured by mass method, b relationship between the signal intensity, $\operatorname{Sig} \operatorname{Int}(y, t=5785 \mathrm{~min})$, measured at the elapsed time $t=5785 \mathrm{~min}$ in Fig. 16a and the water content, $\beta_{\text {Mass }}(y)$, measured at the elapsed time of $5820 \mathrm{~min}$ in $\mathbf{a}$

around the latewood vessels. From this observation, it was found that liquid water first rises from the bottom to the top through the latewood vessels and then through the earlywood vessels.

When the elapsed time, $t$, passed $27 \mathrm{~min}$, as shown in Fig. 18c, the area where liquid water reached the top surface through the latewood vessels increased to the three regions indicated by the three circles. In addition, one of the thick earlywood vessels indicated by the arrow in Fig. 18c was filled with liquid water. It took a few seconds for liquid water to rise from the bottom to the top surface of the thick vessel. Observations in video mode showed that once liquid water began to rise in the other thick vessel, it reached the top surface in a few seconds, similar to the first vessel. From this observation, it is assumed that when liquid water is supplied to the bottom of the test log, liquid water rising in the vessel depends on the capillary force and on accidental triggers such as vibration and fluctuation.

The water penetration mechanism due to capillary force has been demonstrated in several papers (Zhou et. al. 2018; Zhou et. al. 2019). If the penetration of liquid water in the test log is due to capillary force, Fick's law, which considers the water concentration difference as the driving force behind the penetration of liquid water, cannot be applied to understand the water penetration in vessels of a $\log$.

As shown in Fig. 18d-f, the number of water-filled vessels increases with increase in the elapsed time. In Fig. 18f, seven arrows indicate seven freshly filled earlywood vessels during the 66 min separating it from Fig. 18e. In addition, in Fig. 18f, four earlywood vessels already filled with liquid water are indicated by four white arrows. It can be seen that about half of the earlywood vessels were filled with water when $126 \mathrm{~min}$ had passed. Note that water-filled latewood vessels are not indicated by arrows in this figure because the latewood vessels are too thin to determine if they are filled with water. 
(a)

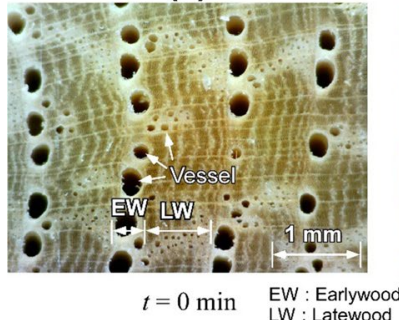

(d)

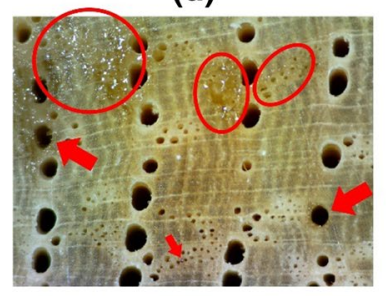

$t=41 \mathrm{~min}$ (b)

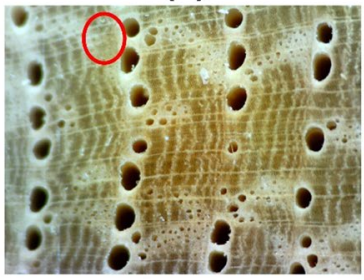

$t=13 \mathrm{~min}$

(e)

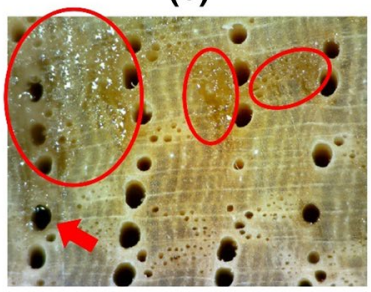

$t=60 \mathrm{~min}$ (c)

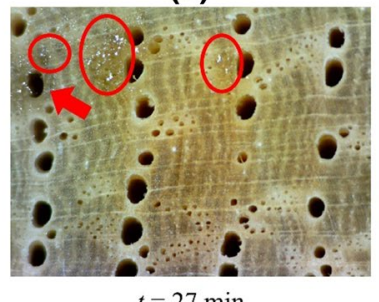

(f)

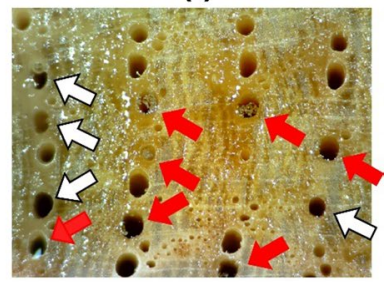

$t=126 \mathrm{~min}$

Fig. 18 Photographs of the top surface of the disk log (sample E). Liquid water was supplied to the bottom surface of the log disk at elapsed time $t=0$. Water-filled vessels indicated by circles and arrows increase with increase in the elapsed time, $t$

\section{Mechanism of liquid water rising in a vessel by capillary force}

From the observation with the optical microscope of liquid water rising in vessels, it was considered that the driving force for liquid water to rise in a vessel is capillary force. The capillary force raises the liquid water in the circular tube, and the height, $h$, of the liquid water is expressed by the following equation:

$$
h=\frac{2 \sigma \cos \theta}{\rho g R}
$$

where $\sigma$ is the surface tension of liquid water, $\theta$ is the contact angle between the inner wall surface of a vessel and the surface of liquid water, $R$ is the radius of the vessel, $\rho=\left(\rho_{\mathrm{H} 2 \mathrm{O}}-\rho_{\text {Air }}\right)$ is the density difference between liquid water and air, and $g$ is the gravitational acceleration. Some reports have pointed out that capillary force in vessels is a driving force for liquid water penetrating along the longitudinal direction in wood (Zhou et al. 2018). Here, note the value of the contact angle, $\theta$, used in Eq. (8). The contact angle cannot be measured directly by observing a liquid water droplet on the inner wall surface of the vessel as the vessel is too small. We can only estimate the contact angle.

Based on the optical observation, the following model is considered for the mechanism of rising liquid water in the vessel. The contact angle, $\theta$, strongly depends on the water content, $\beta$, of the cell wall of the vessel. When $\beta$ exceeds FSP, $\theta$ exceeds 90 degrees because the surface of the cell wall is easily wetted by free water. In 
other words, when $\beta$ exceeds FSP, liquid water rises in the vessel due to capillary force as shown in Eq. (8).

Immediately after the bottom surface of the log disk touches the liquid water in the water storage, liquid water permeates into the wood fibers at the bottom of the $\log$ disk and the water content of the wood fibers increases. As shown in Fig. 19a, when the water content of the test $\log$ is uniform $(\beta>$ FSP $)$, the capillary force acting on the liquid water in the thin latewood vessel is larger than that in the thick earlywood vessel. For this reason, the liquid water in the thin latewood vessel rises faster than the liquid water in the thick earlywood vessel. Since the inner diameter of the latewood vessel is very thin $(10-20 \mu \mathrm{m})$ and the capillary force acts strongly, in the case of a circular pipe with good wettability such as glass, it is estimated that the time for liquid water to reach a height of $4 \mathrm{~mm}$ (corresponding to the thickness of the log disk) is within 1 s. However, in the actual observation shown in Fig. 18, it took more than $10 \mathrm{~min}$ for the liquid water to reach the top surface of the log disk through the earlywood vessels. It was thought that this large time difference is due to the time it takes for liquid water to diffuse into the wood fibers and thus increase the water content of wall surface of a vessel.

If capillary force is the driving force for rising water, the velocity of the rising water should be orders of magnitude faster. To explain the significant decrease in the velocity of rising water, a model was presented without any experimental evidence in which the contact angle of water depends on the water content of the wall cells in the vessel. The paper by Zhou et al. (2019) also pointed out that the cause of the slow velocity of rising water is the contact angle of water in the vessel and that the contact angle changes depending on the water content of the wall cells. The relationship between contact angle and water content has not been presented in any reports and in the present experiment, and thus, this model is not supported by sufficient experimental evidence.

As shown in Fig. 19a, the liquid water rising in the latewood vessel is absorbed by the cells on the wall surface of the vessel and diffuses to the surrounding wood fiber portions thus increasing their water content, $\beta$. The water content distribution in the wood fiber parts illustrated at the top of the figure shows the water content

(a)

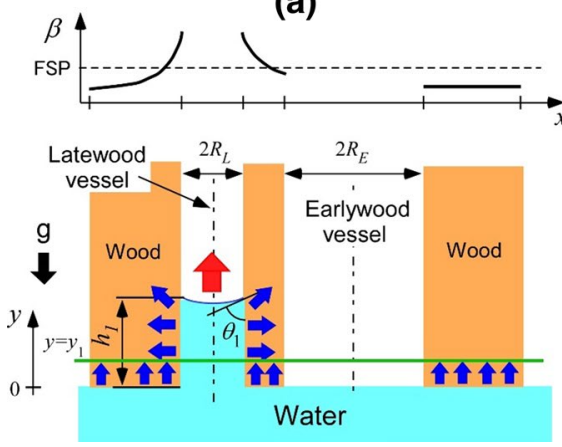

(b)
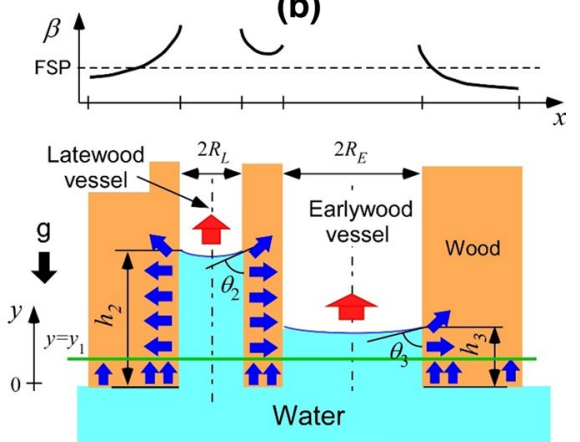

Fig. 19 Schematic drawing of the mechanism by which liquid water rises first in the latewood vessel and then rises in the earlywood vessel 
on the line at $y=y_{1}$ in the figure below. As a result, $\theta_{1}$ becomes $90^{\circ}$ or less even in the upper part of the latewood vessel, and the liquid water in the latewood vessel rises even further. It is assumed that the liquid water rises in the latewood vessel by repeating this procedure.

The liquid water rising in the latewood vessel diffuses into the surrounding wood fibers and also increases the water content around the earlywood vessel on the right side. As $\beta$ of the wall surface of the earlywood vessel increases, $\theta_{3}$ of liquid water in the earlywood vessel becomes $90^{\circ}$ or less, and the liquid water rises in the earlywood vessel as shown in Fig. 19b. It is supposed that the above mechanism causes the liquid water to rise first in the latewood vessel, and then in the earlywood vessel.

\section{Explanation of MR image by liquid water rising in vessels}

To explain the time-dependence change in the signal intensity of the MR images in Figs. 14 and 15, schematic drawings showing the two processes of liquid water rising in vessels and the diffusion into the wood fibers are presented in Fig. 20. Figure $(\mathrm{a}-\mathrm{c})$ illustrate in the upper part of the figures how the liquid water rises in the vessels and fills all vessels when the liquid water is supplied to the bottom surface of the dried log disk. Figure 20d-f illustrate in the lower part of the figures how the liquid water in the vessels diffuses into the wood fibers around the vessels after liquid water supply is stopped, and the liquid water in the vessels disappears. Note that the vertical axis of the figures shows the water content, not the height of liquid water. In the figures, the initial water content $\left(\beta_{\mathrm{i}}=14 \%\right)$ and the water content of FSP of the log disk are shown as a guideline for the water content, $\beta$. The water content of FSP was considered to be $20 \%$, determined from the minimum water content visualized in the MR image.

Figure 20a shows the schematic drawing in which liquid water first rises in one latewood vessel. It is believed that in which of the many latewood vessels the liquid water rises depends on accidental and probabilistic phenomena such as vibration and fluctuation. The rising liquid water in the vessel is diffused to the wood fibers around the vessel, so that the water content of the wood fiber exceeds the water content of FSP after a while. Although the liquid water in the vessel is lost as a result of diffusion to wood fibers, the liquid water in the vessel is not reduced because liquid water is usually supplied through the vessel from the bottom surface of the log disk. After that, as shown in Fig. 20b, the water content near the adjacent vessel increases and the liquid water rises in the adjacent latewood vessel. As the liquid water rises, the water content of the wood fibers around the vessel further rises beyond the water content of FSP. After that, as shown in Fig. 20c, the water content around the earlywood vessel increases, and finally the liquid water rises in the earlywood vessel. In this way, liquid water first rises in the latewood vessel, and then liquid water rises in the earlywood vessel, and finally the water content of the wood fibers around the vessel increases beyond the water content of FSP.

Since the liquid water in the vessels is free water, $T_{2}$ relaxation time constant of liquid water is as long as $10 \mathrm{~ms}$ or more (Müller et al. 2001; Gezici-Koç et al. 2017; Cai et al. 2020; Hiltunen et al. 2020). On the other hand, $T_{2}$ relaxation time constant 

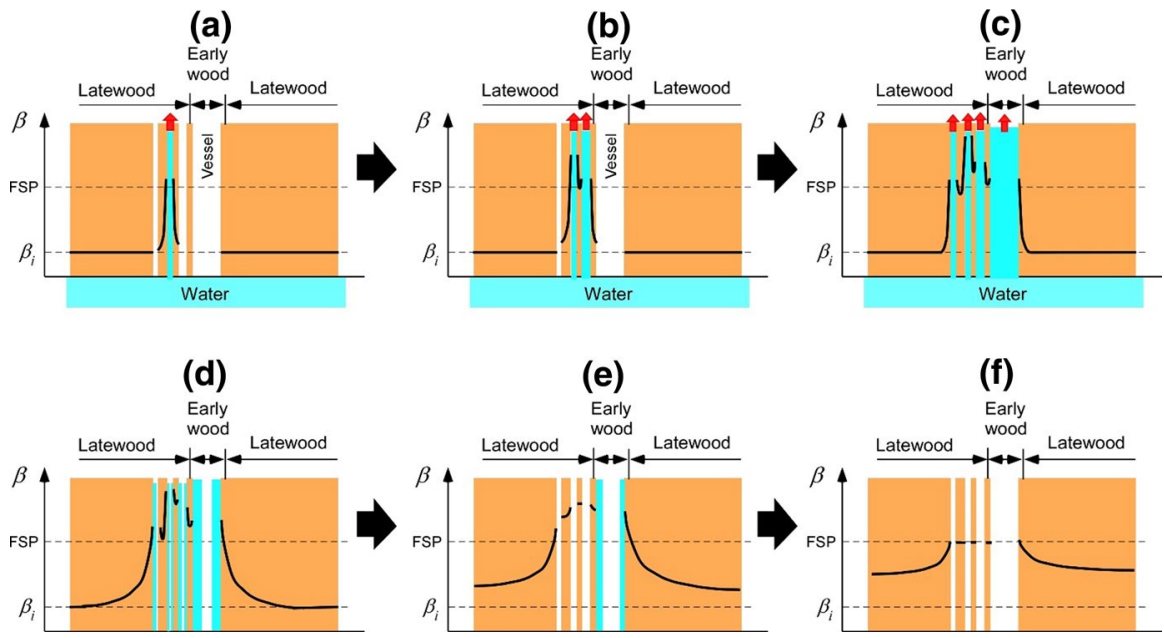

Fig. 20 Schematic drawings of the process of liquid water rising in latewood vessels and earlywood vessels, a-c When liquid water is supplied to the bottom surface of the dried log disk, liquid water rises in the vessels and diffuses to wood fibers around the vessels. $\mathbf{d}-\mathbf{f}$ When the supplied water is removed from the bottom surface of the log disk, liquid water in vessels diffuses into the surrounding wood fibers around the vessels and then disappears from the vessels

of water bound to cellulose or hemicellulose is $1 \mathrm{~ms}$ or less, which is very short. From comparing the MR images shown in Fig. 14 with Fig. 20a-c, it is thought that the increase in the signal intensity of the MR image with increase in water supply time corresponds to the increase in the number of vessels filled with liquid water.

Next, the bottom part of Fig. 20 shows that the liquid water in vessels diffuses to wood fibers around the vessels when the supplied water is removed from the bottom surface of the log disk and the water supply is stopped. As shown in Fig. 20d, the water content, $\beta$, of the wood fibers around the vessels increases because the liquid water in the vessels diffuses into the surrounding wood fibers. Correspondingly, liquid water in the vessels is reduced since liquid water is not supplied. After that, as shown in Fig. 20e, since the surface area-to-volume ratio of the latewood vessel is larger than that of the earlywood vessel, the liquid water in the latewood vessel disappears first owing to water diffusion. It is thought that the time when the liquid water in the latewood vessels disappear corresponds to the time when the signal intensity drops sharply at the elapsed time $t=280 \mathrm{~min}$ shown in Fig. 16b. After that, the liquid water still remaining in the earlywood vessel diffuses into the surrounding wood fibers and finally disappears. As shown in Fig. 20f, when the water content drops to FSP, the water diffusion in the wood fiber parts becomes very slow since the free water disappears. Compared with the MR image of Fig. 15, the signal intensity of the MR image is high because the vessels are filled with liquid water immediately after the water supply is stopped. Since the amount of liquid water having a long $T_{2}$ relaxation time constant diffuses into the wood fibers over time and decreases, the signal intensity of the MR image is reduced over time. This is the reason why the signal intensity of the MR image decreased significantly with the 
passage of time even though the water uptake mass absorbed in the test log hardly decreased.

\section{Conclusion}

The water uptake mass and effective diffusion coefficient of water penetrating test logs (Quercus serrata) were measured in order to evaluate how much the water uptake changes depending on whether or not shiitake mycelium grows in the test logs. Six test logs were used and stood in the direction of gravity. Liquid water was supplied to the test log from the bottom. Water uptake mass of the test log was measured for $20 \mathrm{~h}$. The effective diffusion coefficient, $D_{\text {eff }}$, was calculated from time change of the water uptake mass based on Fick's diffusion law. The $D_{\text {eff }}$ of test logs in which shiitake mycelium grew was $1.5-3.4 \times 10^{-8} \mathrm{~m}^{2} / \mathrm{s}$, and the values increased 2.4-4.7 times from that of the dried $\log$. On the other hand, the $D_{\text {eff }}$ of moldy $\operatorname{logs}$ was 6.7 to $9.7 \times 10^{-10} \mathrm{~m}^{2} / \mathrm{s}$, which was $0.058-0.081$ times that of dry test logs. Based on the observation results of the water penetration process into a log disk by MRI and an optical microscope, it was considered that the driving force for liquid water to rise in the longitudinal direction in the test $\log$ is the capillary force acting in the vessel. In addition, the reason why the signal intensity of the MR image of the test $\log$ decreases with the passage of time is because the liquid water in the vessels is diffused into the wood fibers, and so the $T_{2}$ relaxation time constant of water in the $\log$ becomes shorter.

Supplementary Information The online version contains supplementary material available at https://oi. org/10.1007/s00226-021-01313-6.

Acknowledgements This research was supported by a research grant from Keio University (2020).

\section{References}

Arima S (1999) Effect of moisture condition to incubate Shiitake bed-logs. Bull Oita Mush Res Inst $1: 1-24$

Barry KM, Pearce RB, Evans SD, Hall LD, Mohammed CM (2001) Initial defense responses in sapwood of Eucalyptus nitens (Maiden) following wounding and fungal inoculation. Physiol Mol Plant P 58:63-72

Brownstein KR (1980) Diffusion as an explanation of observed NMR behavior of water absorbed on wood. J Magn Reson 40:505-510

Bucur V (2003) Nondestructive characterization and imaging of wood. Springer, Berlin

Burr HK, Stamm AJ, (1956), Diffusion in wood, Information Reviewed and Reaffirmed, 1674 https:// www.google.co.jp/url?sa $=\mathrm{t} \& \mathrm{rct}=\mathrm{j} \& \mathrm{q}=\& \mathrm{esrc}=\mathrm{s} \&$ source $=\mathrm{web} \& \mathrm{~cd}=\& \mathrm{ved}=2 \mathrm{ahUKEwjC} 4-\mathrm{y} 4 \mathrm{zYj}$ xAhXLwYsBHTNTCZ4QFjAAegQIBRAD\&url=https\%3A\%2F\%2Fir.library.oregonstate.edu\% 2Fdownloads\%2Fth83m3056\&usg=AOvVaw3TSpRMetPqJ-s1v3PYzMZ5. Accessed 25 January 2021

Cai C, Javed MA, Komulainen S, Telkki VV, Haapala A, Heräjärvi H (2020) Effect of natural weathering on water absorption and pore size distribution in thermally modified wood determined by nuclear magnetic resonance. Cellulose 27:4235-4247 
Callaghan PT (2006) Principles of nuclear magnetic resonance microscopy. Oxford Science Publications, Oxford

Candanedo L, Derome D (2005) Numerical simulation of water absorption in softwood. In: Ninth international IBPSA conference Canada. pp. 123-130

Chang SJ, Olson JR, Wang PC (1989) NMR imaging of internal features in wood. Forest Prod J 39:43-49

Frankl J (2013) Changes in swelling and water absorption of wood degraded by brown rot fungi. Adv Mater Res 778:818-822

Gezici-Koç Ö, Erich SJF, Huinink HP, van der Ven LGJ, Adan OCG (2017) Bound and free water distribution in wood during water uptake and drying as measured by $1 \mathrm{D}$ magnetic resonance imaging. Cellulose 24:535-553

Hall LD, Rajanayagam V (1986) Evaluation of the distribution of water in wood by use of three-dimensional proton NMR volume imaging. Wood Sci Technol 20:329-333

Hameury S, Sterley M (2006) Magnetic resonance imaging of moisture distribution in Pinus sylvestris L. exposed to daily indoor relative humidity fluctuations. Wood Mat Sci Eng 1:116-126

Hiltunen S, Mankinen A, Javed MA, Ahola S, Venäläinen M, Telkki VV (2020) Characterization of the decay process of Scots pine caused by Coniophora puteana using NMR and MRI. Holzforschung. https://doi.org/10.1515/hf-2019-0246

Hunter AJ (1993) On movement of water through wood-The diffusion coefficient. Wood Sci Technol 27:401-408

Khazaei J (2008) Water absorption characteristics of three wood varieties. Cercetări Agronomice în Moldova 41(2): 134

Kleinberg R (1995) Encyclopedia of nuclear magnetic resonance. In: Harris RK (ed) Grant DM. Wiley, New York

Krus M, Kunzel HM (1993) Determination of $\mathrm{D}_{\mathrm{w}}$ from A-value. IEA Annex XXIV Report T3-D-93/02

Kumaran MK (1999) Moisture diffusivity of building materials from water absorption measurements. J Therm Env Bldg Sci 22:349-355

Kuroda K, Kanbara Y, Inoue T, Ogawa A (2006) Magnetic resonance micro-imaging of xylem sap distribution and necrotic lesions in tree stems. IAWA J 27:3-17

MAFF (2019) The 93rd statistical yearbook of ministry of agriculture, forestry and fisheries. https:// www.maff.go.jp/e/data/stat/93th/index.html. Accessed 25 January 2021

MEXT (2016) Standard tables of food composition in Japan - 2015 - (Seventh Revised Version) Ministry of Education, Culture, Sports, Science and Technology https://fooddb.mext.go.jp/. Accessed 25 January 2021

Müller U, Bammer R, Halmschlager E, Stollberger R, Wimmer R (2001) Detection of fungal wood decay using magnetic resonance imaging. Holz Roh Werkst 59:190-194

Nakada R (2014) Wetwood in trees; appearance and definition. Mokuzai Gakkaishi 60(2):63-79 ((In Japanese))

Noorolahi S, Khazaei J, Jafari S (2008) Modeling cyclic water absorption and desorption characteristics of three varieties of wood. In: AALD AFITA WCCA2008

Ogawa K, Yashima T (2019) MRI visualization of shiitake mycelium growing in woodchip blocks used for shiitake mushroom cultivation. Magn Reson Imaging 58:90-96

Ogawa K, Yashima T (2020) MRI visualization of shiitake mycelium growing in logs in order to support shiitake mushroom log cultivation. Cellulose. https://doi.org/10.1007/s10570-020-03407-z

Okoh ET (2014) Water absorption properties of some tropical timber species. J Energy Nat Resour $3(2): 20-24$

Pearce RB, Sümer S, Doran SJ, Carpenter TA, Hall LD (1994) Non-invasive imaging of fungal colonization and host response in the living sapwood of sycamore (Acer pseudoplatanus L.) using nuclear magnetic resonance. Physiol Mol Plant P 45:359-384

Pearce R, Fisher B, Carpanter T, Hall L (1997) Water distribution in fungal lesions in the wood of sycamore, Acer pseudoplatanus, determined gravimetrically and using nuclear magnetic resonance imaging. New Phytol 135:675-688

Przbylowicz P, Donoghue J (1988) Shiitake growers handbook: the art and science of mushroom cultivation. Kendall Hunt Pub Co, Dubuque

Tokimoto K (2010) The foundation of shiitake cultivation on logs. Jpn Soc Mushroom Sci Biotechnol $18: 131-138$

Wang PC, Joseph S (1989) Nuclear magnetic resonance imaging of wood. Wood Fiber Sci 18(2):308-314

Wasser SP (2005) Shiitake (Lentinus edodes) In: Encyclopedia of dietary supplements, Marcel Dekker, New York 653-664. https://doi.org/10.1081/E-EDS-120024880 
Zhou M, Caré S, Courtier-Murias D, Faure P, Rodts S, Coussot P (2018) Magnetic resonance imaging evidences of the impact of water sorption on hardwood capillary imbibition dynamics. Wood Sci Technol 52:929-955

Zhou M, Caré S, King A, Courtier-Murias D, Rodts S, Gerber G, Aimedieu P, Bonnet M, Bornert M, Coussot P (2019) Wetting enhanced by water adsorption in hygroscopic plantlike materials. Phys Rev Res 1:033190

Publisher's Note Springer Nature remains neutral with regard to jurisdictional claims in published maps and institutional affiliations. 